\title{
BEHAVIORAL PROBLEMS OF THE HEARING-IMPAIRED STUDENTS IN THE SULTANATE OF OMAN: TEACHERS PERSPECTIVE STUDY
}

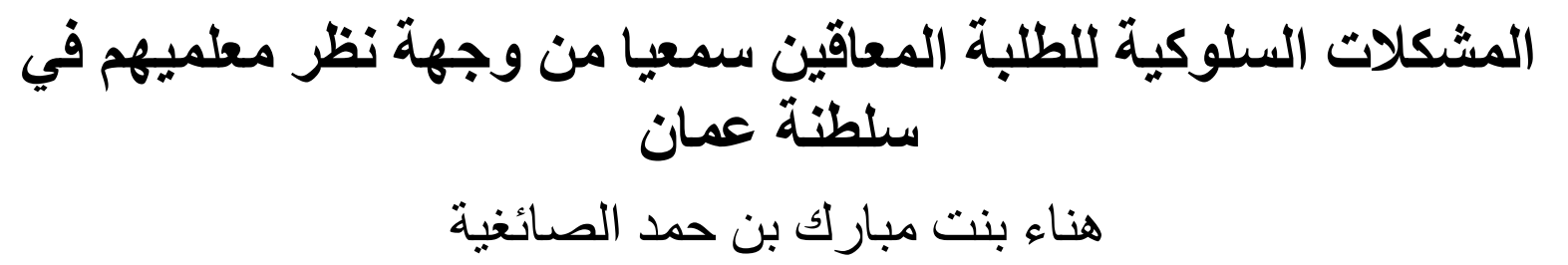

\author{
Hanaa Mubark Hamed AL-Saighi ${ }^{1 \star}$ \& Dr. Ismail Hassanein Ahmed ${ }^{2}$ \\ ${ }^{1}$ Ph.D. Candidate in Education at International Islamic University Malaysia (IIUM); \\ hanaa.alsaghi@moe.om \\ ${ }^{2}$ Assoc. Prof. Dr. in Education at International Islamic University Malaysia (IIUM); \\ tulib52@iium.edu.my \\ ${ }^{*}$ Corresponding Author
}

\begin{abstract}
This quantitative study discusses the level of behavioral problems of the hearing impaired from the viewpoint of their teachers in the Sultanate of Oman, and the problem lies in the loss of this category of hearing sense or its presence in a simple manner, which leads to difficulty in communication and interaction with those around the hearing impaired; this affects their behavior and makes it socially unacceptable, Which requires finding proposals or solutions that help the hearing impaired in harmony and integration with their normal teachers and peers. The study aimed to diagnose the behavioral problems of hearing impaired students (deaf, hard of hearing, cochlear implant) from the viewpoint of their teachers, as well as to analyze the factors that lead to reducing the behavioral problems of the hearing impaired. The study relied on the descriptive analytical approach. The study population consisted of all the teachers and hearing impaired teachers, who numbered (266) teachers. The study sample included all members of the study community. The researcher used a questionnaire comprising (32) expressions of behavioral problems for the disabled: the problem of aggression (9 phrases), the problem of excessive activity (6) phrases, the problem of abuse (7) phrases, the problem of lying (6) phrases, and the problem of social withdrawal (4) phrases. The results showed that the level of behavioral problems of students ranged between medium and low, first came the problem of excessive activity, then the problem of aggression, followed by the problem of social withdrawal, the problem of lying, and finally the problem of abuse. The researcher recommended: integrating the hearing impaired completely into the school community in terms of (morning assembly, and participation in school activities).
\end{abstract}

Keywords: behavioral problems, hearing impaired, teachers and teachers. 


\section{الملخص}

تتاقش هذه الدر اسة الكمية مستوى المشكلات السلوكية للمعاقين سمعيا من وجهة نظر معلميهم في

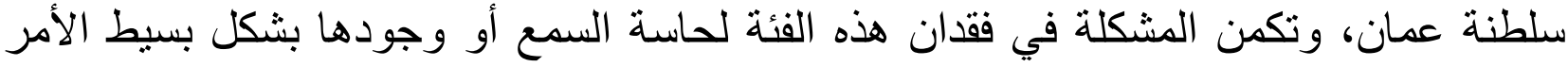

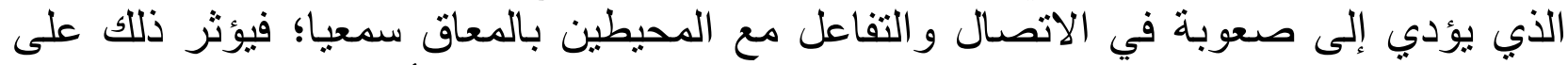
سلوكهم ويجعله غير مقبول اجتماعيا، مما يستوجب إيجاد إيجاد مقترحات أو حلول تساعد المعاقين

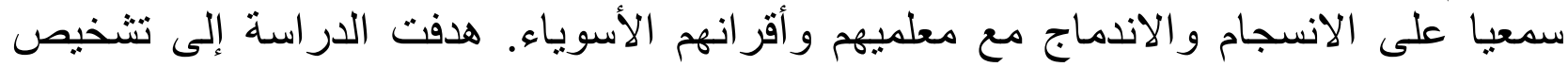

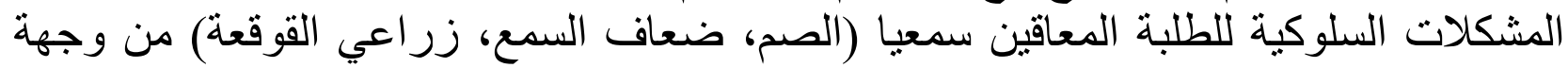

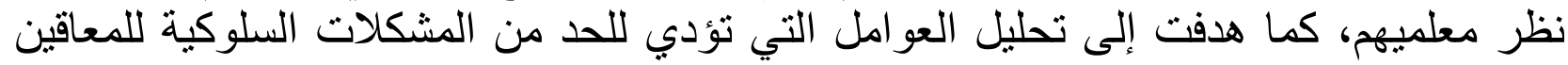

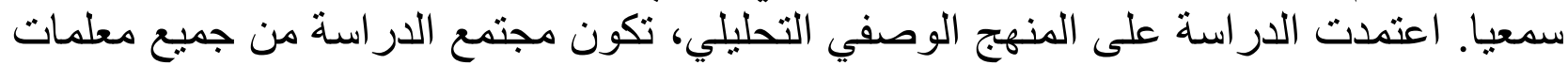

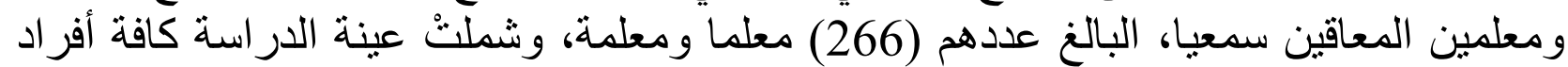
مجتمع الدراسة. استخدمت الباحثة استبيان يضم (32) عبارة عن المشكلات السئل السلوكية للمعاقين:

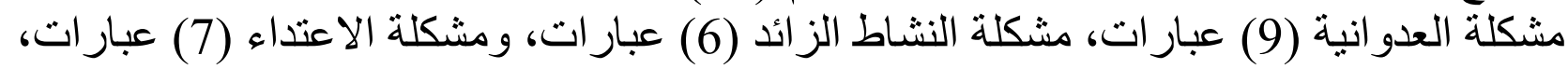
ومشكلة الكذب (6) عبار ات، ومشكلة الانسحاب الاجتماعي (4) عبار ات. بينت النتائج: تراوح

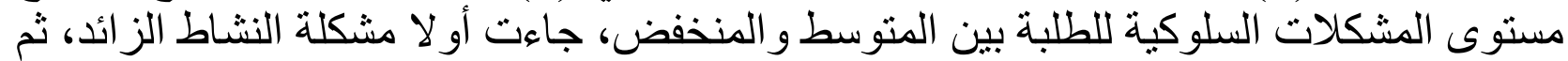
مشكلة العدوانية، تلتها مشكلة الانسحاب الاجتماعي، فمشكلة الكذب، وأخيرا مشكلة الاعتداء. أوصت الباحثة: دمج المعاقين سمعيا دمجا كليا في المجتمع المدرسي من حيث (طابور الصباح، و المشاركة في الأنشطة المدرسية). الكلمات المفتاحية: المشكلات السلوكية، المعاقين سمعيا، المعلمون و المعلمات.

حظي ذوو الاحتياجات الخاصة من الباحثين و الدارسين و المتخصصين بعناية مميزة، فأصبح لهم اهتمام، ومتابعة خاصة دن جميع النو احي النفسية و السلوكية والاجتماعية. ويعتبر الطلبة المعاقين

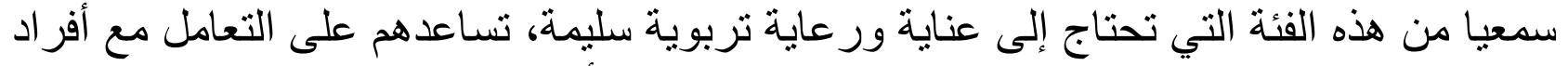
المجتمع، وقد تصنف الإعاقة السمعية حسب العمر الزمني، أو حسب موضع الإصنابة في الجهاز السمعي، أو حسب شوة شئمة الفقدان السمعي.

و لأن حاسة السمع لها دور هام في حياة الأفراد للتفاعل والتواصل مع أفراد المجتمع وتطور

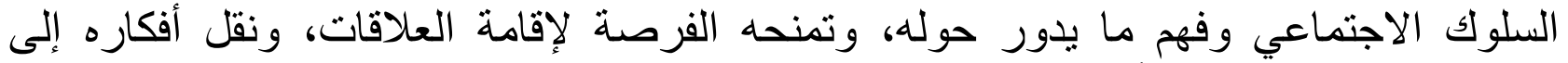

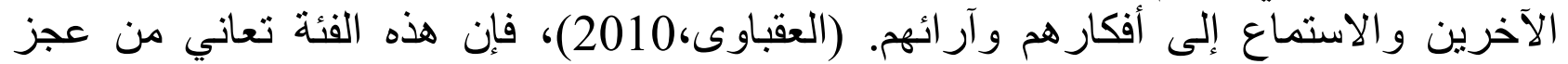

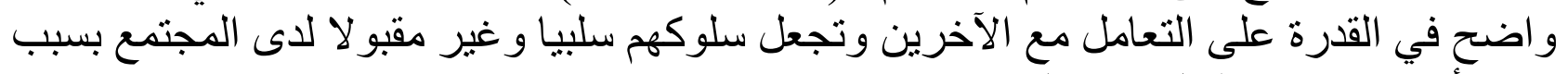

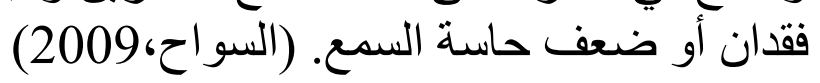

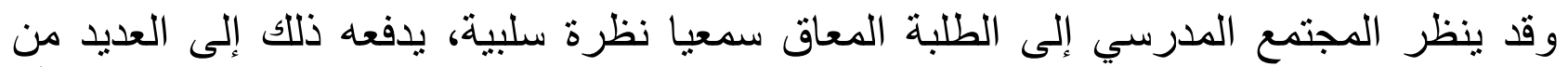

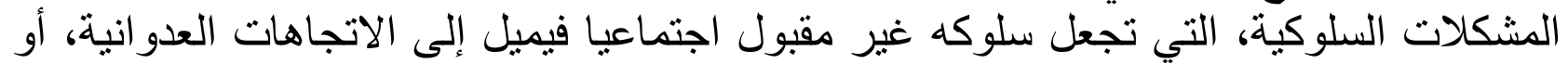

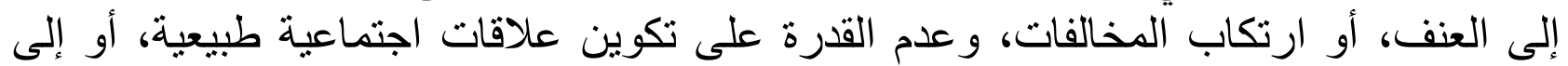

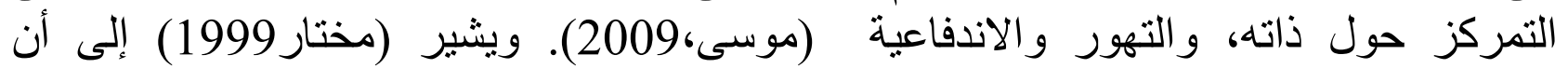
المشكلات السلوكية ترجع إلى ظروف غير مناسبة بعيشها الطلبة ونؤثر على صحتهم النفسية 


\section{و وعلى سلوكياتهم وتعاملهم مع الآخرين.}

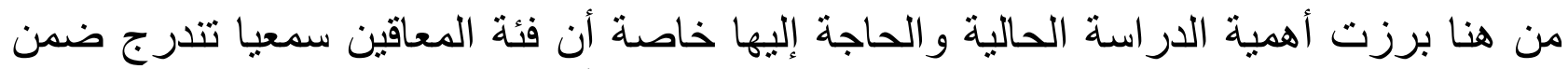

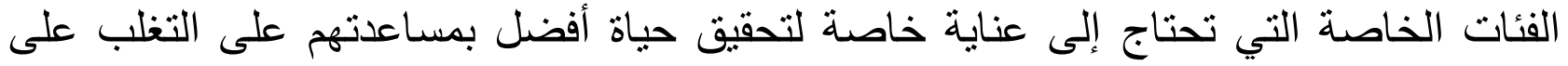
المشكلات السلوكية.

مشكلة الار اسة:

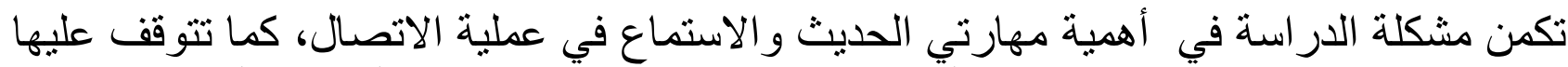

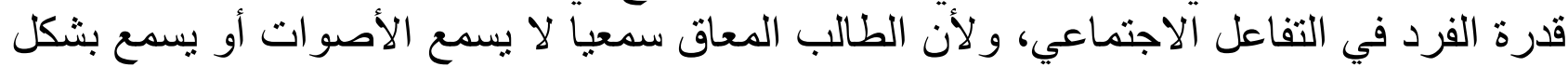

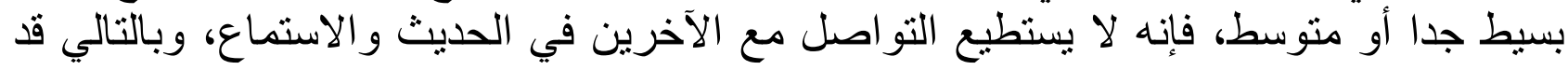

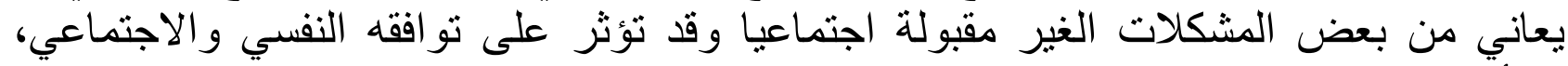

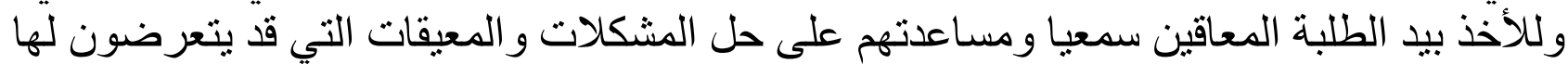

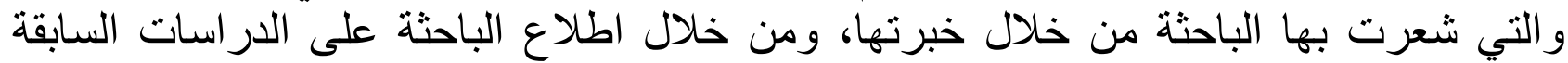

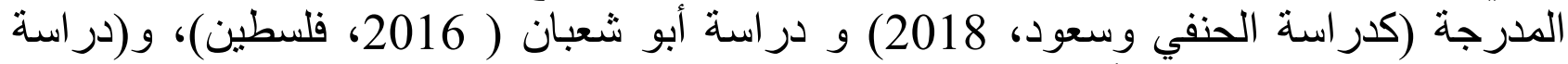

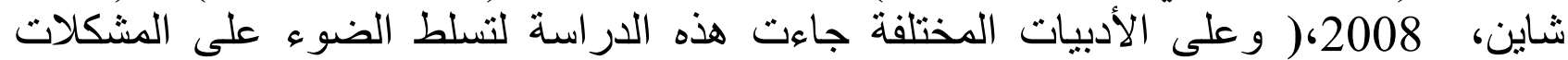

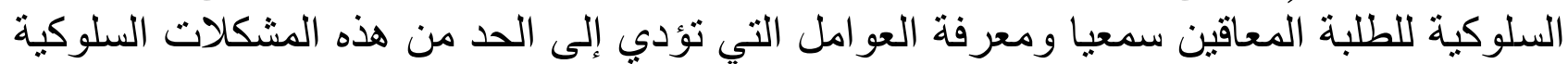

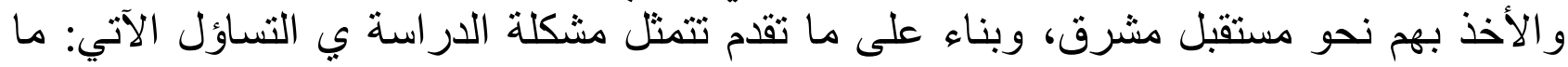
المشكلات السلوكية التي يعاني منها الطلبة المعاقين سمعيا من وجهة نظر معلميهم في سلطنة

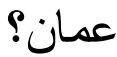
أهداف الاراسة:

أ_تشخيص مستوى المشكلات السلوكية لطلبة ذوي الإعاقة السمعية من وجهة نظر معلميهم في سلطنة عمان. بـتحليل العوامل التي تؤدي إل الحد من المشكلات السلوكية لطلبة ذوي الإعاقة السمعية من وجهة نظر معلميهم في سلطنة عمان. الإطار النظري: مفهوم المشكلات السلوكية: ذكر عو اد وز امل (2011) في تعريف المشكلات السلوكية بأنها عبارة عن اضطر اب في شخصية

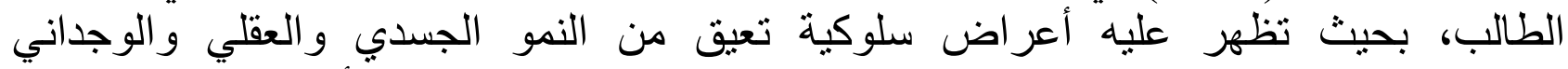

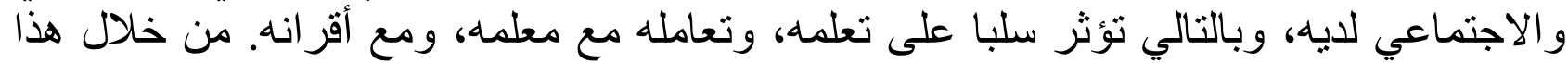

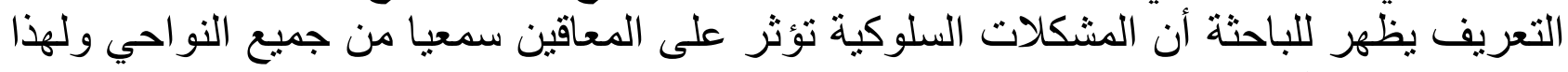
تحتاج إلى تسليط الضوء عليها لمعالجنها. العوامل المؤدية للمشكلات السلوكية: 1- العو امل المدرسية:

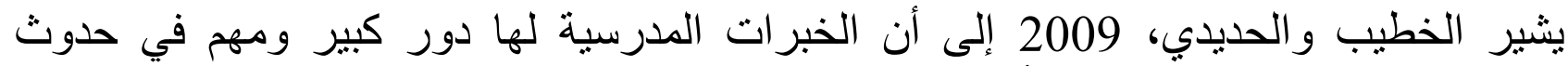
المشكلات السلوكية مستندا إلى أن بعض الطلبة لم يكن لديهم مشكلات سلوكية قبل الالتحاق فئ فئ 
بالمدرسة ومع ذلك ليس هناك دليل علمي يثبت صحة ذللك. و لأساليب المعلمين دور كبير في

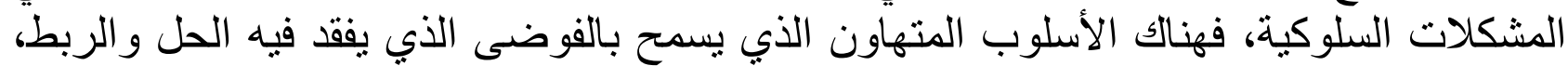

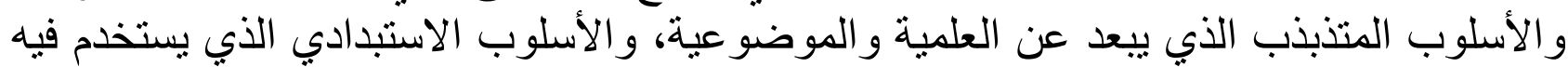
المعلم الأساليب القسرية بأنو اعها. (الظاهر،2008).

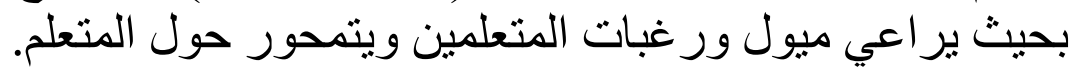

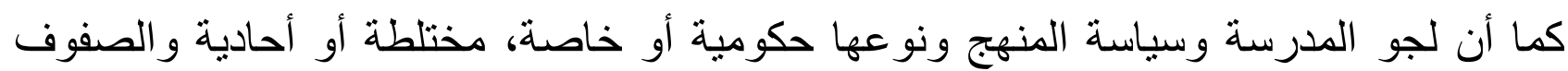
الدراسية وما ينوفر فيها من الماديات جميع هذه الأمور لها دور كبيا كبير في تكيف المنعلم

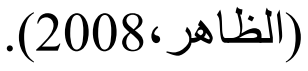
و هناك عو امل أخرى تساهم في وجود المشكلات السلوكية، القدوة، الروتين اليومي، استخدام الثدة الثرة

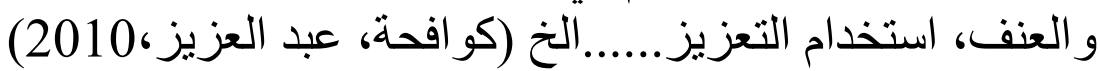

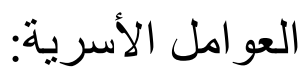

للأساليب الو الدية دور كبير في تكوين شخصية الطالب، فالأطفال الذين بعاملون بالسلطة هم أكثر

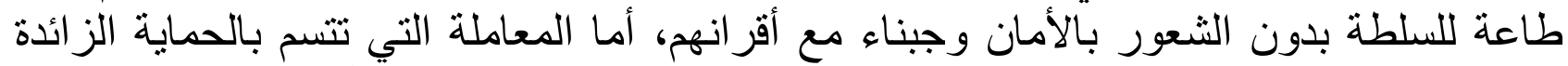

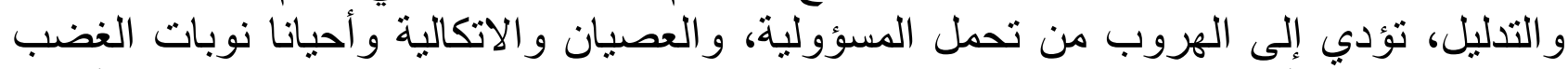

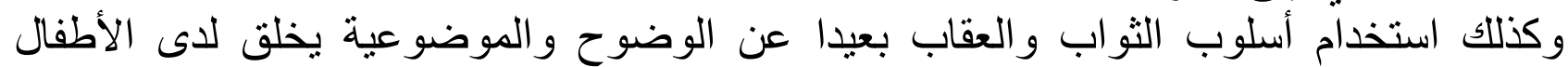

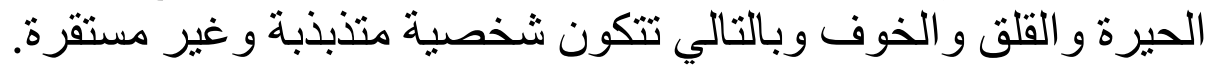

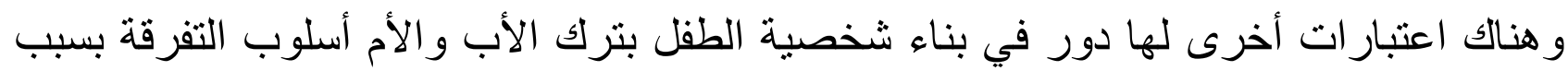

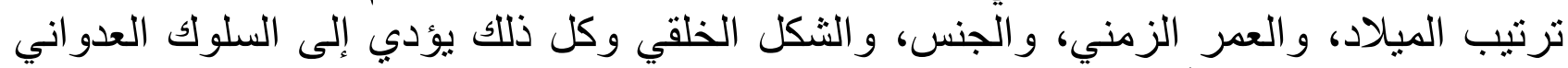

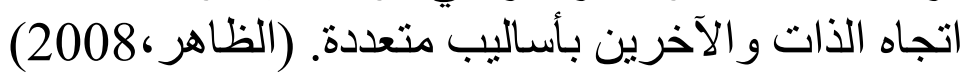

العو امل الثقافية:

يشير رويلر وكينتونك (Ruller \& QuintonK 1976) إلى وجود علاقة وبئة بين الطبقة الاجتماعية

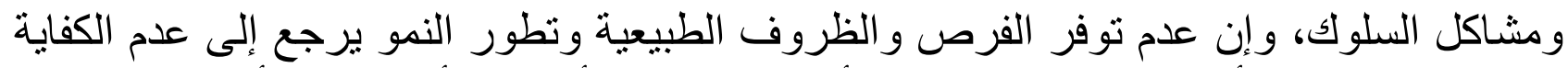

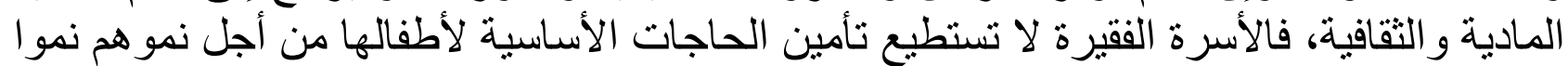

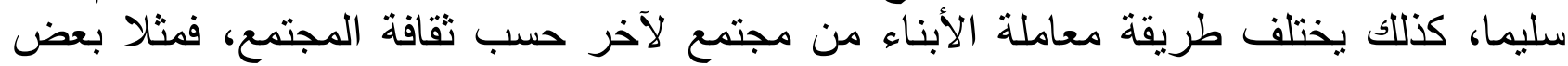

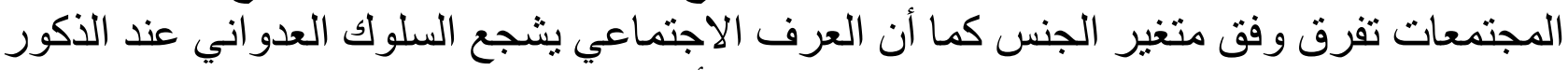

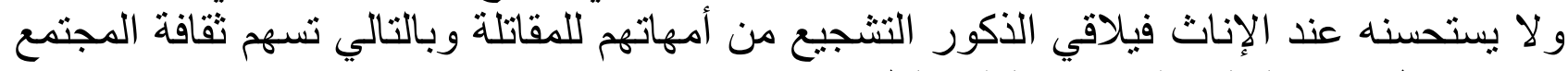
في الاضطر ابات السلوكية والانفعالية. (الظاهر، 2008)

العوامل البيولوجية:

يشير كو افحة، و عبد العزيز،2010 إلى أن السلوك يتأثر وله علاقة بالعو امل البيولوجية. ويذكر

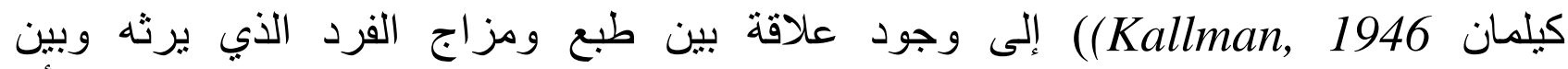

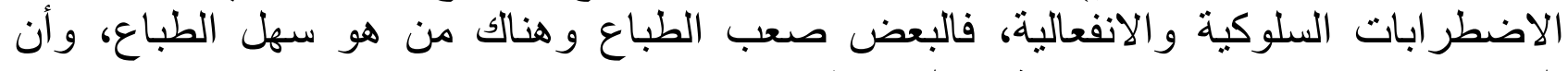

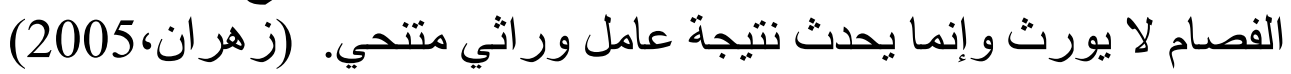

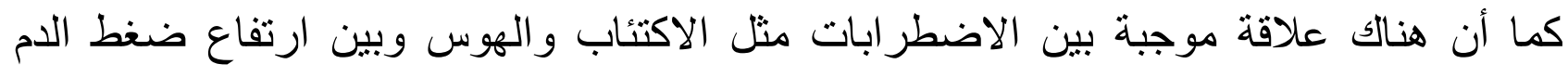


وبعض الالتهابات وتصلب الثر ايين و أمر اض القلب. (القمش، والمعايطة، 2009) مفهوم الإعاقة السمعية:

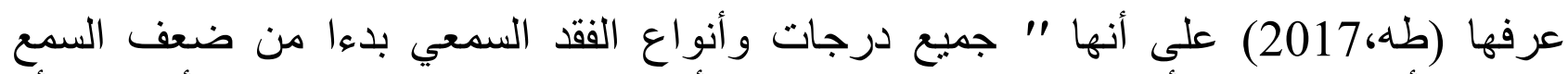

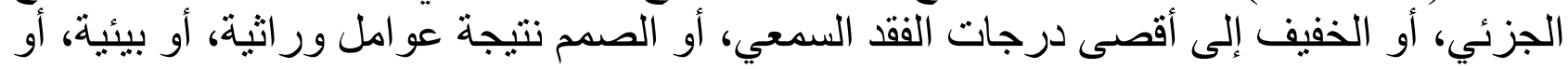

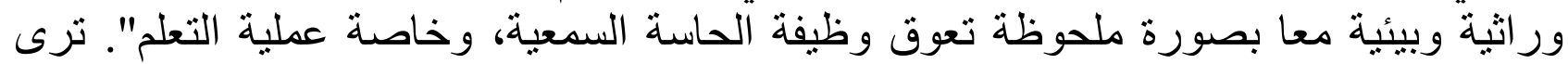

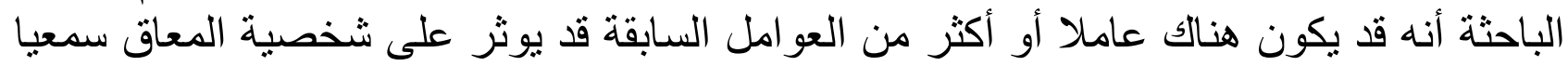

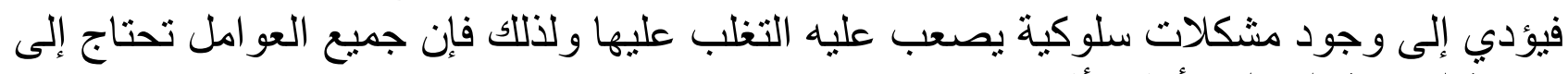
در اسةّة لمعرفة العامل الأكثر تأثير ا.

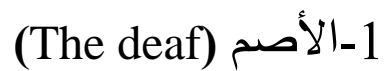

هم الأفراد الذين يعانون من فقدان سمعي يبدأ ب (70) ديسيبل فأكثر بعد استخدام المعينات

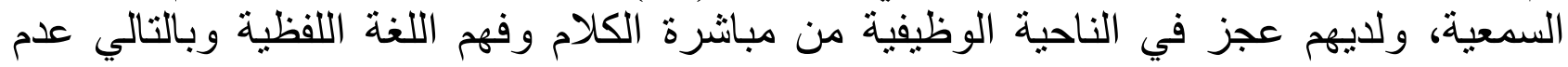

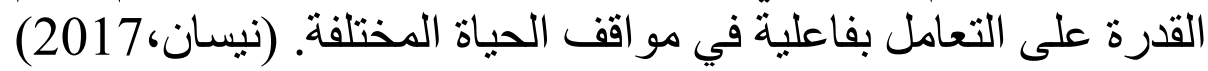

2-ضعيف السمع (hearing impaired):

عرفه (رسلان،2010) بأنه فقد جز عا من قدرته على السمع أو لديه بقايا سمع وباستخدام المعينات

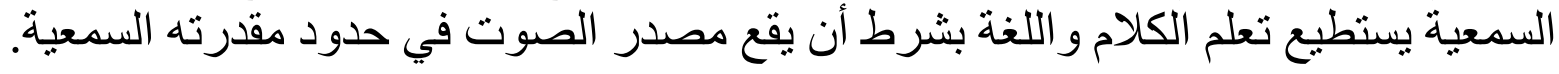

3-3 زارعي القوقعة الإلكترونية: (Cochlear implants)

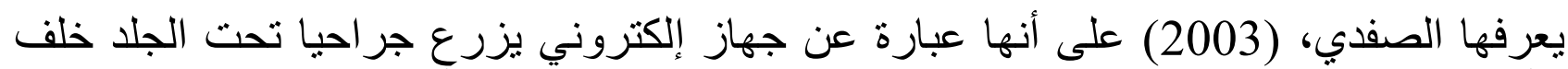

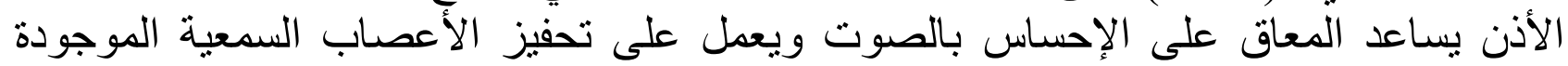
داخل القوقعة.

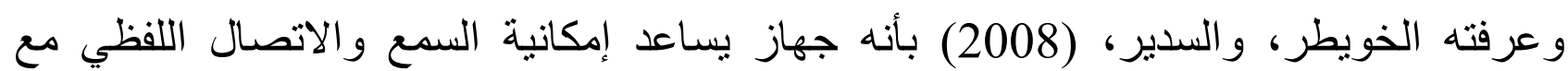

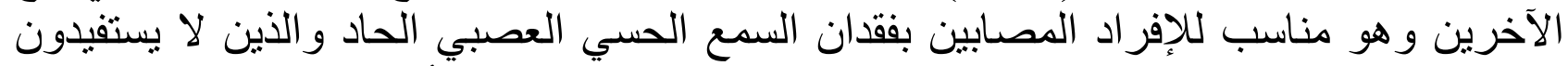

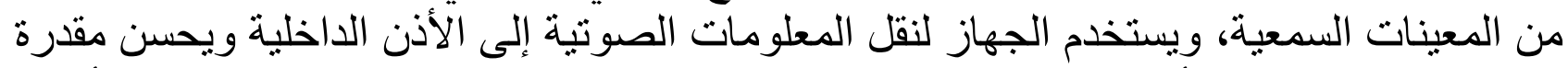

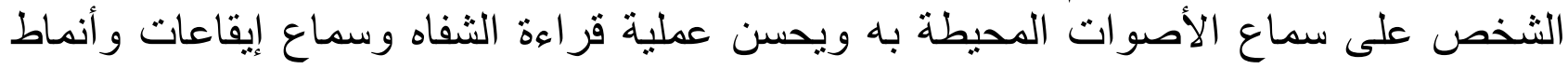
النطق.

الفرق بين الأصم وضعيف السمع: يرى رسلان،(2009) أن الإعاقة السمعية تشمل كل درجات وأنواع واعن الفقد السمعي وبالتالي تعيق

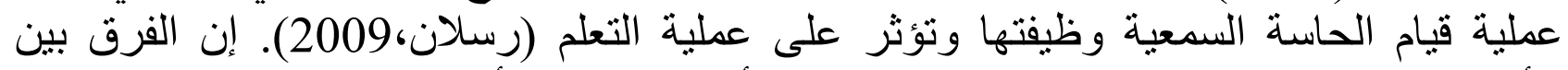

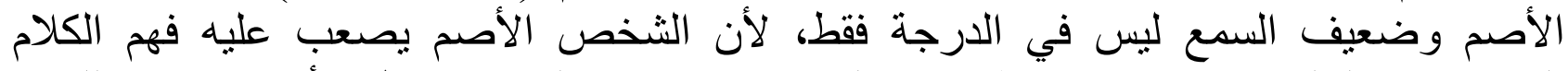

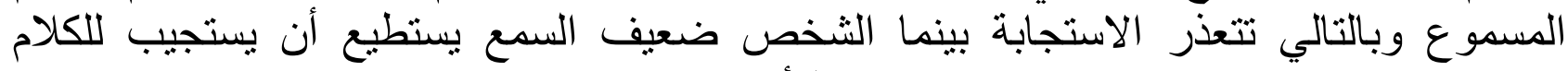

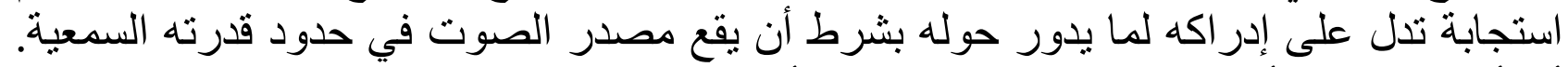
أي أن الثخص الأصم حاسة السمع لدية معطله أما ضعيف السمع السمع يعاني نقصا في قدرته السمعية. (فهمي،1985) كذللك الأشخاص الصم تكون لديهم درجات من الصم غير الوظيفي أما المصابين بضعف السمع 
توجد لايهم درجات من السمع تتضمن درجات من القصور.

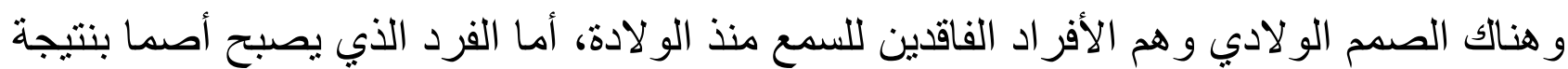

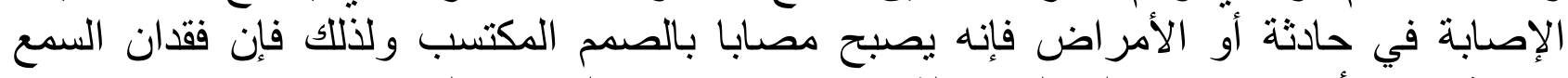

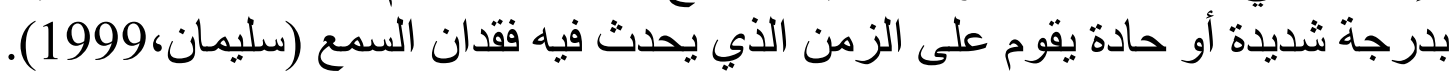

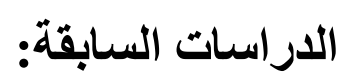

دراسة الحنفي وسعود، (2018) بعنوان" أثر تنمية الذكاء الأخلاقي لاى المعاقين سمعيا في

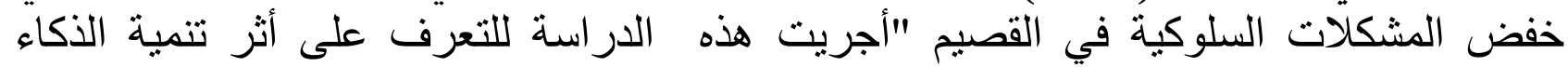

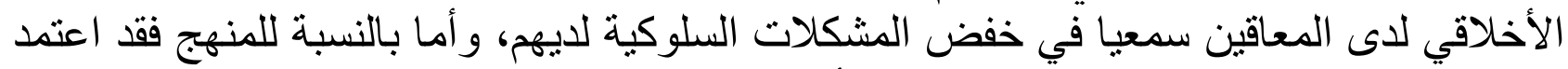

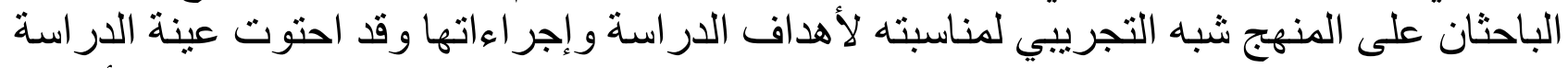

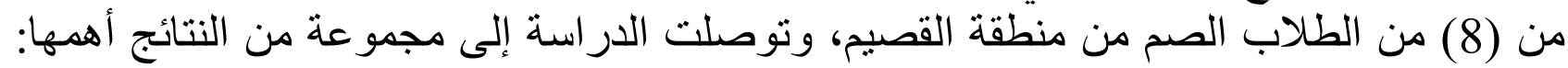

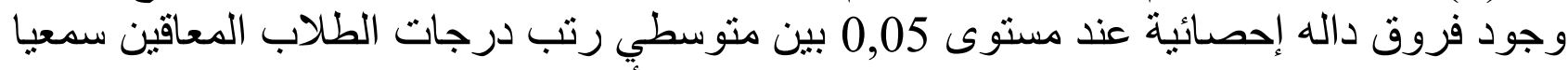

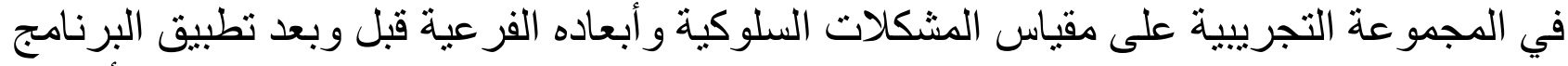

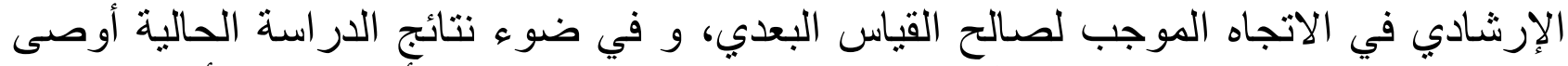

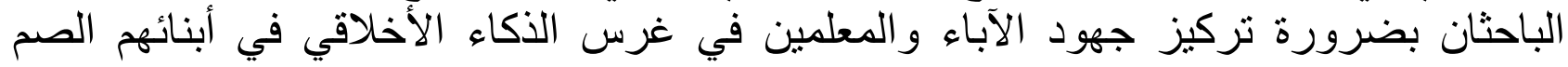
لخفض المشكلات السلوكية.

دراسة أبو شعبان، (2016) بعنوان" المشكلة السلوكية لدى الأطفال ذوي الإعاقة السمعية

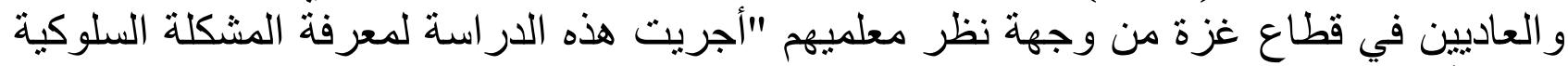

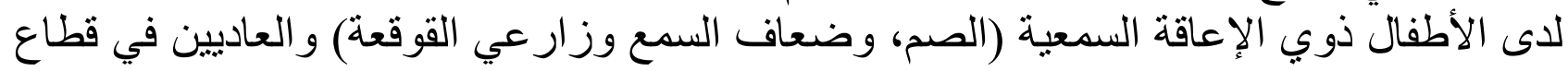

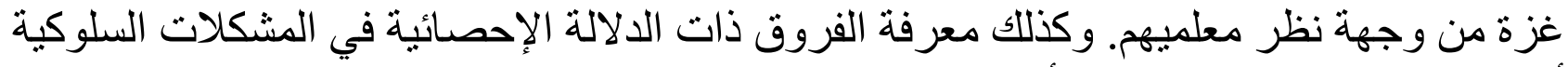

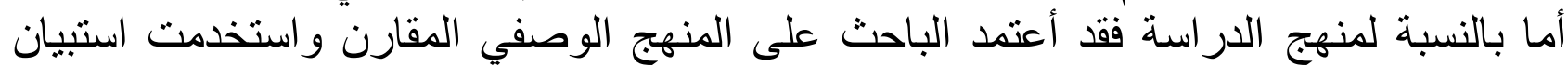

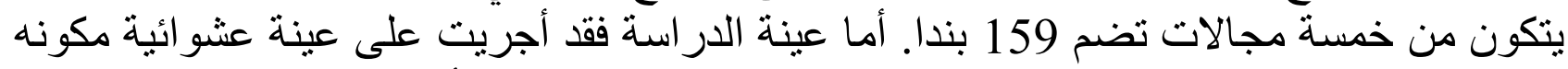

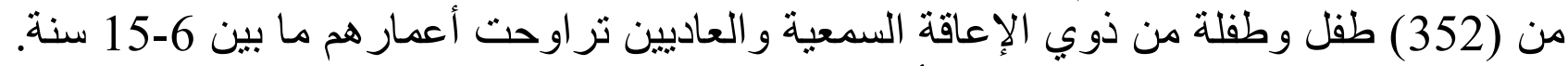

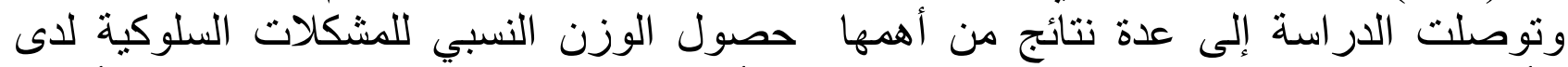

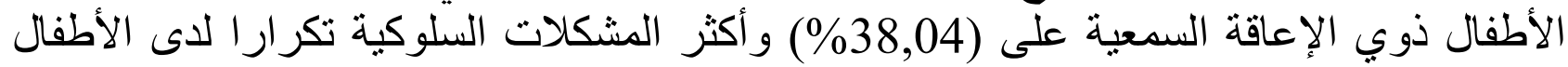

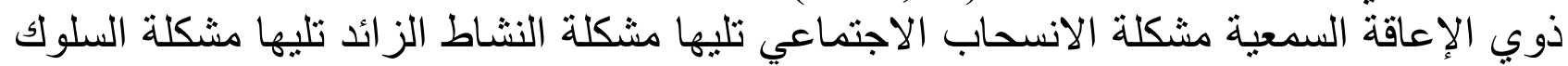

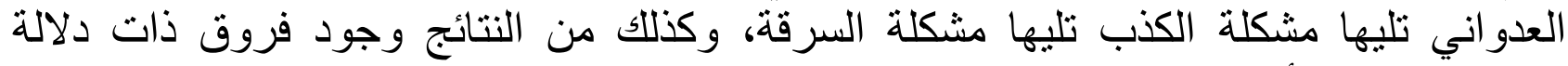

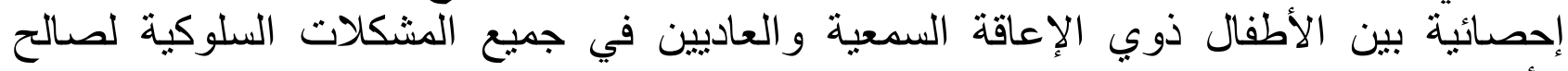

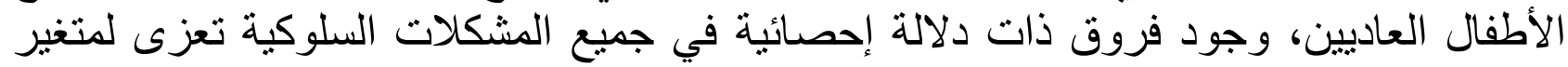

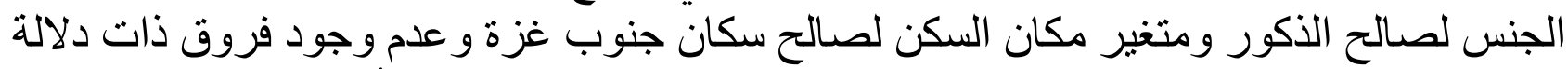

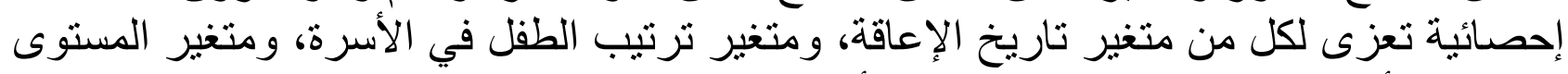

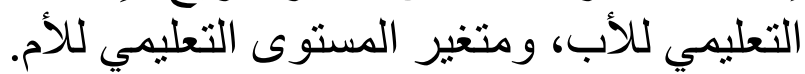

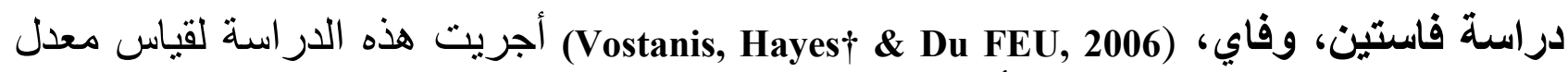

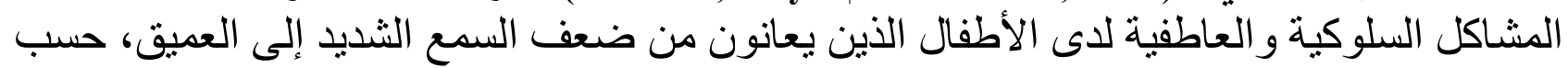

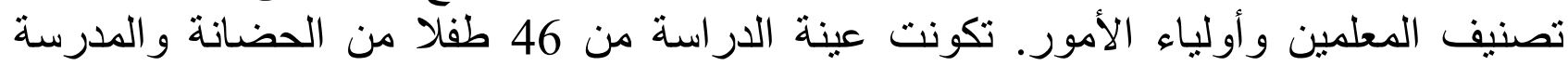

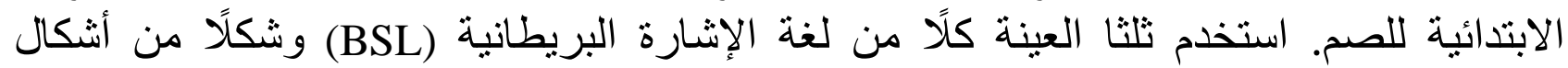

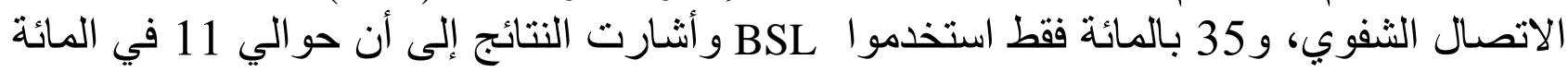




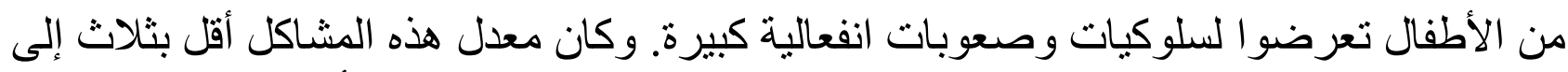

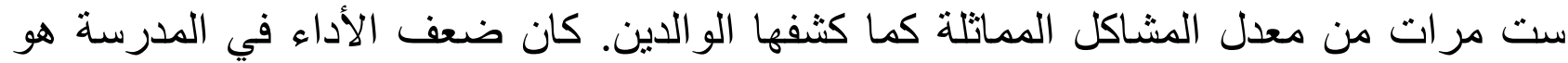

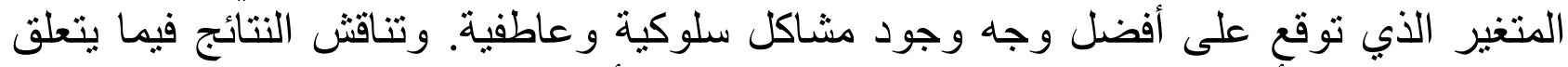

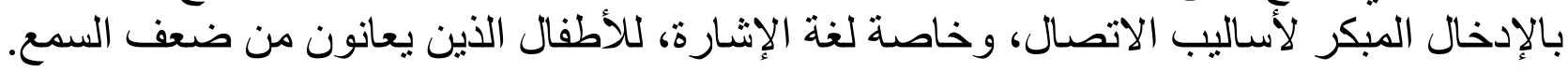

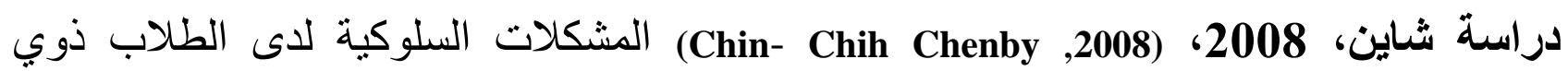

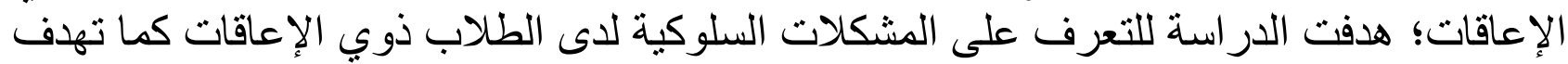

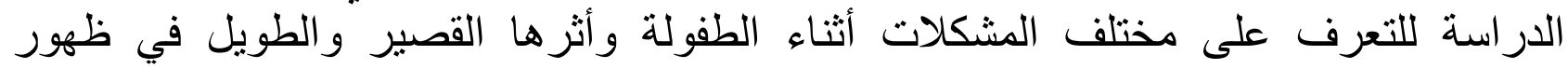

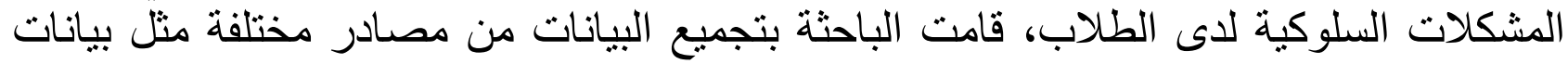

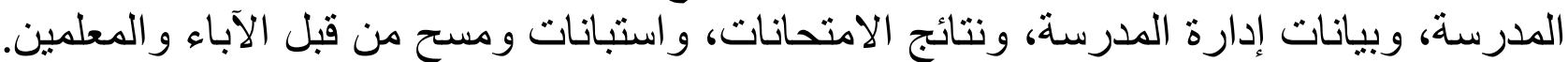

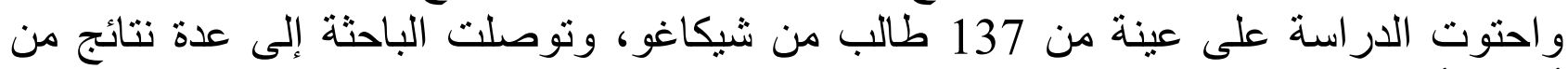
أهمها: أن الطلاب ذوي الإعاقة مرتبطة بالإصابة بمخاطر بالمشكلات السنات السلوكية.

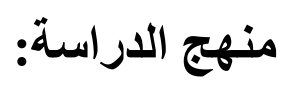

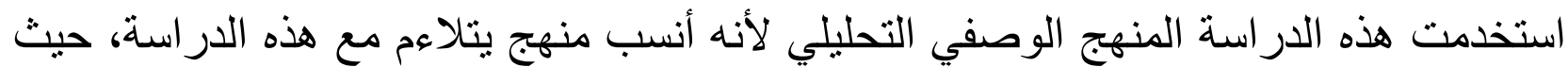

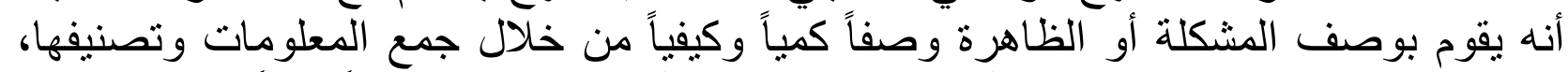

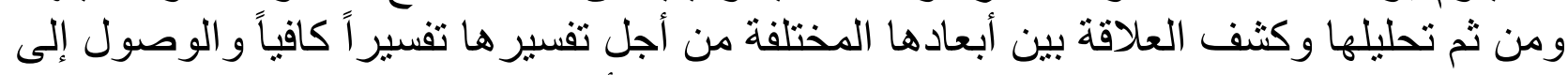

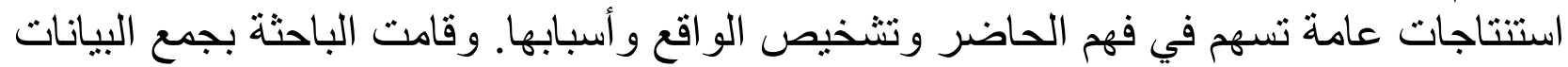

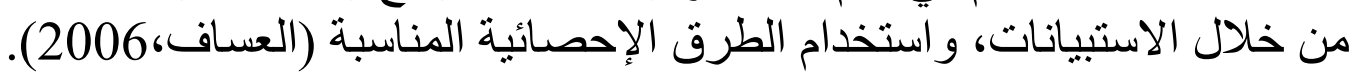

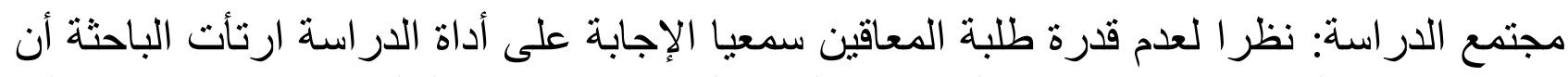

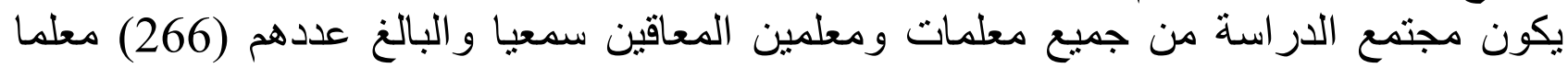
ومعلمة.

عينة الدر اسة: تكونت عينة الدراسة من المعلمين و المعلمات للمعاقين سمعيا، حيث تمثل العينة

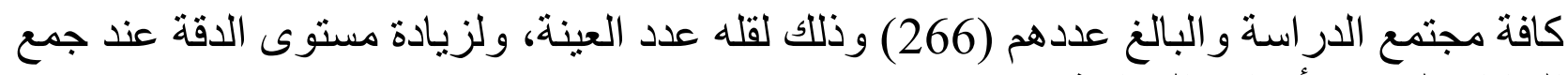
البيانات لتحقيق أهداف الدر الدة النة.

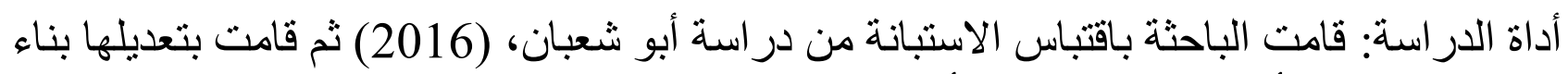

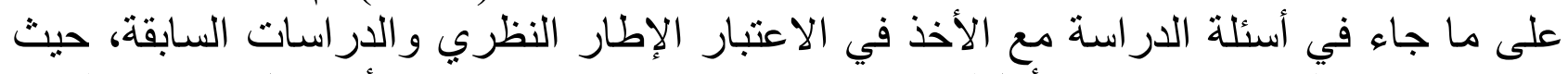

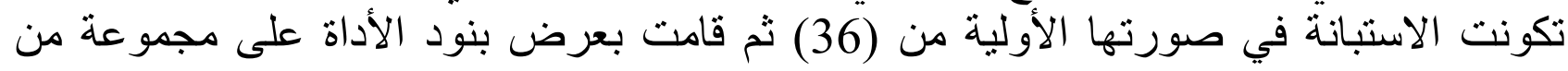

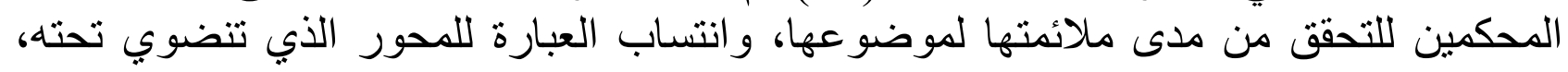

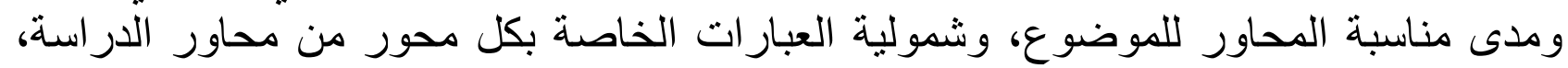

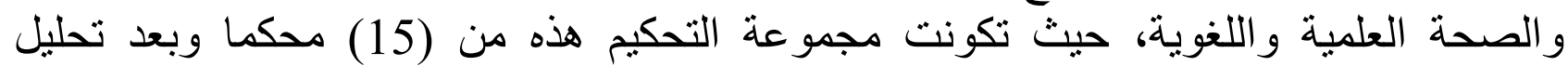

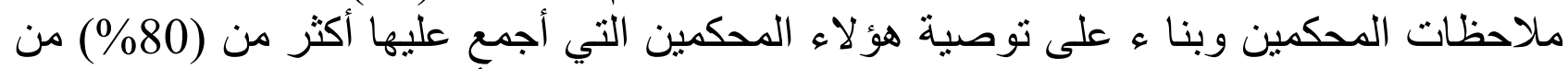

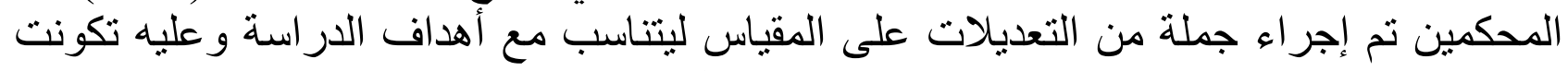

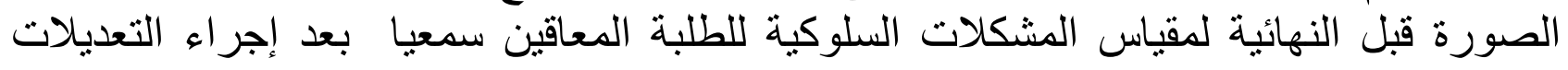

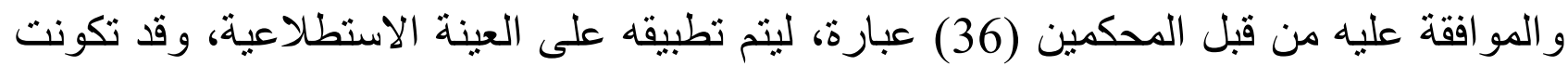

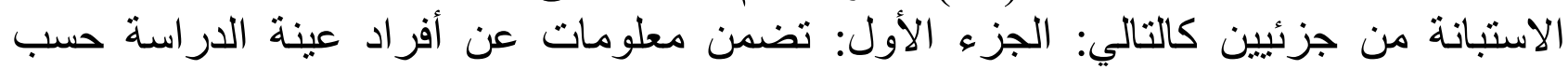
متغيرات الدراسة (الجنس، اللحافظة، نوع الإعاقة، نوع الحلقة)، الجزء الأن الثاني: تضمن (36) 


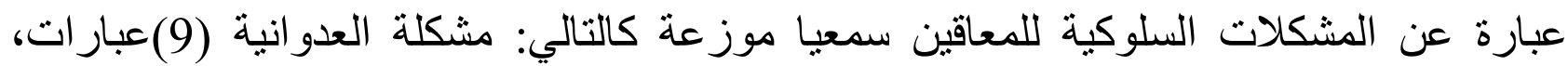

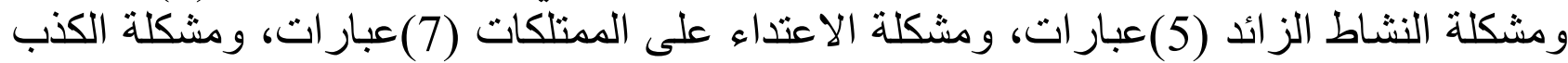

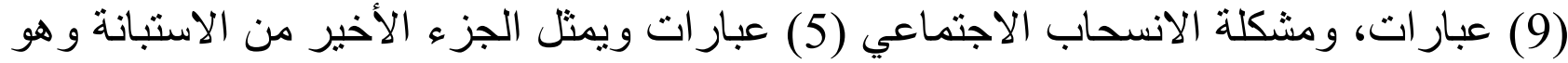

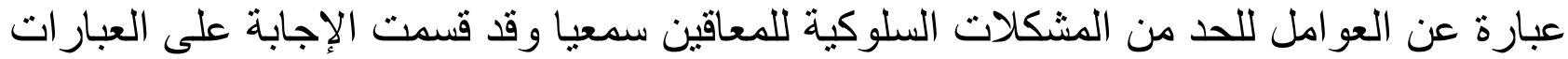

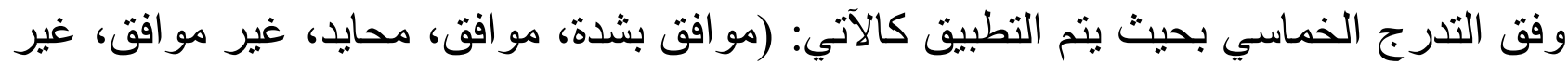

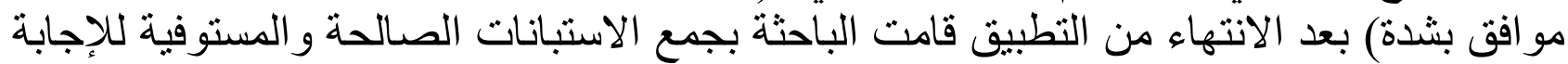

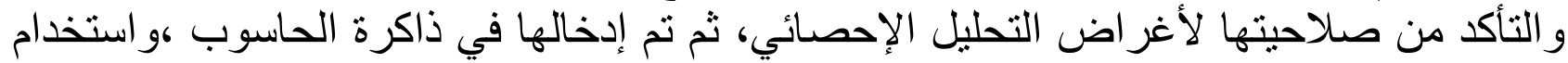

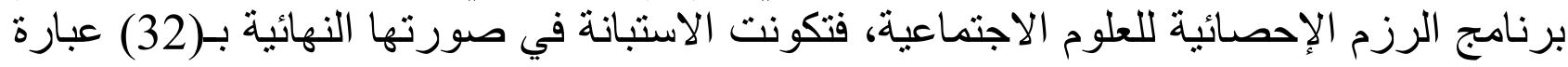

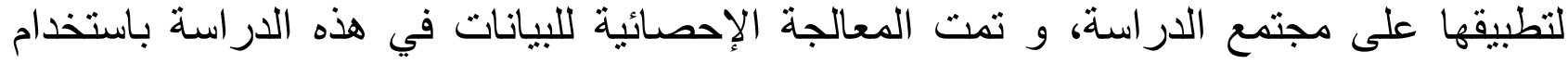
برنامج الرزم الإحصائية للعلوم الاجتماعية.

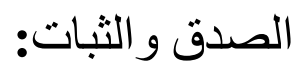

أو لا: الصدق الظاهري: عرضت الأداة على مجموعة من المحكمين للتحقق من مدى ملانئمتها

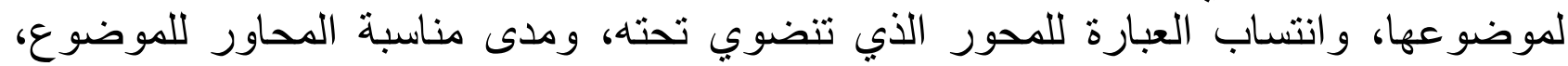

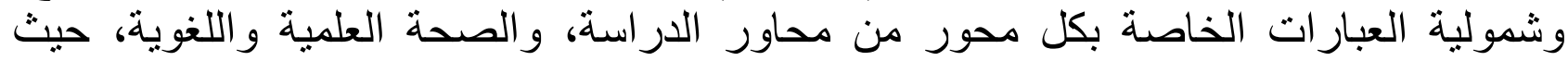

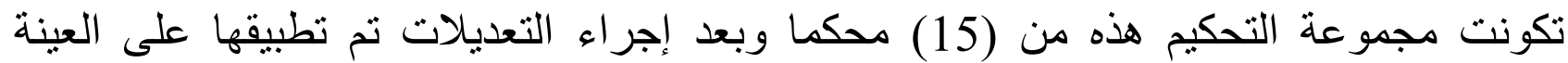

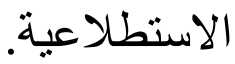

ثانيا: صدق الاتساق الداخلي: جرى التحقق من صدق الاندة الاتساق الداخلي للاستبانة بتطبيق الاستبانة

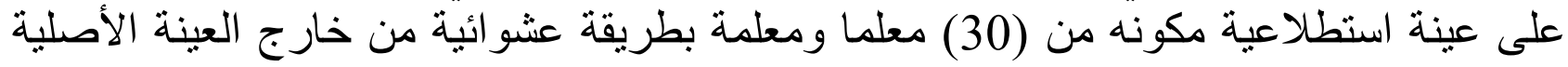

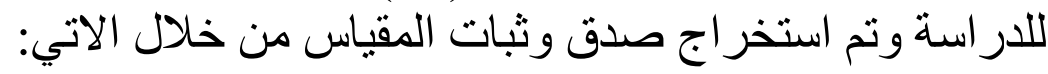

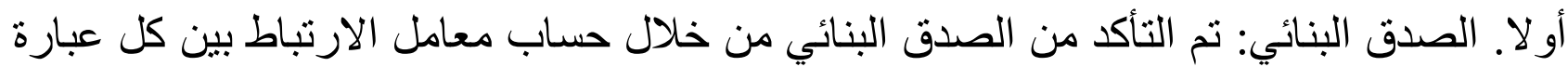

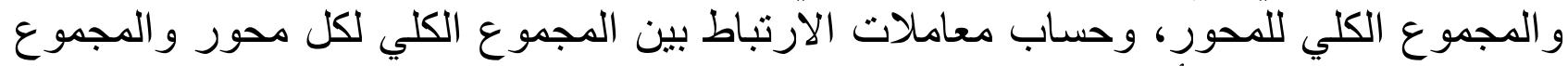
الكلي للمقياس، و اتضح أن المقياس يتمتع بصدق البناء ما عدا بعض العباس العبار آت قامت الباحثة بحذفها من المقياس

ثانيا. ثبات المقياس: تم التحقق من ثبات المقياس وفق الطر ائق الآتي:

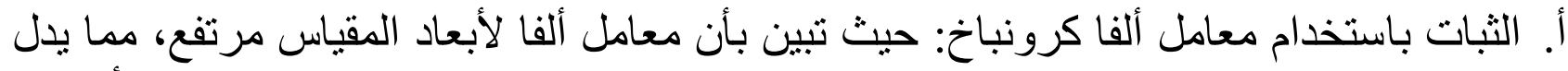

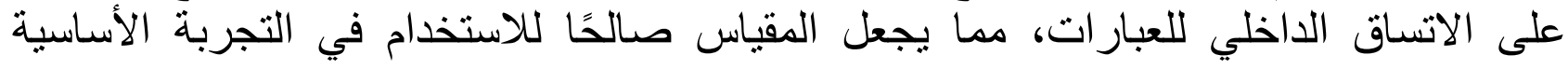

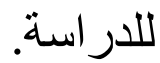

ب. الثبات بطريقة التجزئة النصفية: حيث تبين أن معامل الثبات بالتجزئة النصفية مرتفع وهذا يدل على ثبات المقياس ويجعله صالحًا للتطبيق في التجربة النهات الأساسية لعينة الدراسة. نتائج الدر اسة: أو لا: المتوسطات الحسابية والانحر افات المعيارية ومستوى المشكلات السلوكية بالنسبة لمحاور

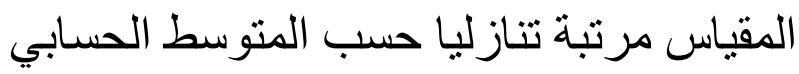
الجدول (1) مستوى المشكلات السلوكية بالنسبة لمحاور المقياس مرتبة تنازليا 


\begin{tabular}{|c|c|c|c|c|}
\hline المشكلات & الالتحرياري & المتوسط الحسي & المشكلات السلوكية & b \\
\hline متوسطة & .90 & 2.63 & النشاط الز ائد & 1 \\
\hline منوسطة & .88 & 2.52 & العدو انية & 2 \\
\hline متوسطة & .69 & 2.47 & الانسحاب الاجتماعي & 3 \\
\hline منوسطة & .90 & 2.35 & 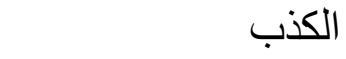 & 4 \\
\hline منخفضة & .84 & 2.32 & ممتلكات الأخرين $\quad$ على & 5 \\
\hline متوسطة & .75 & 2.46 & الكلي & \\
\hline
\end{tabular}

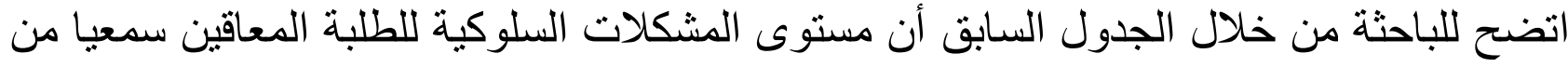

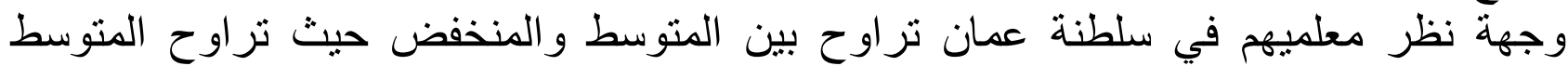

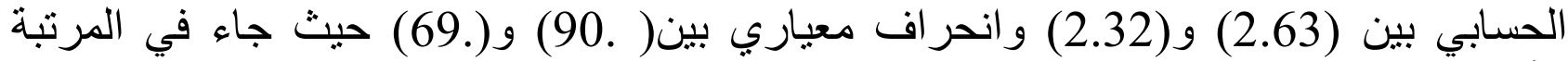

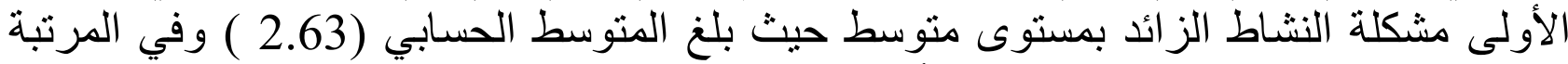

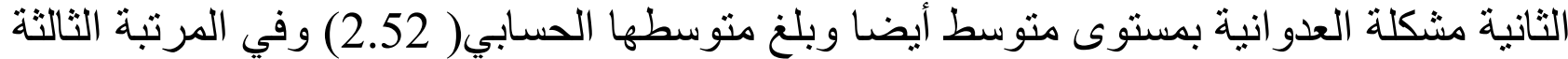

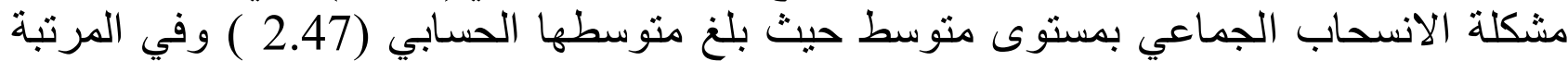

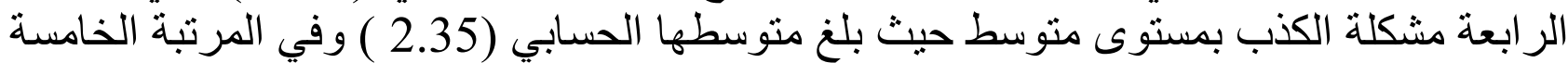

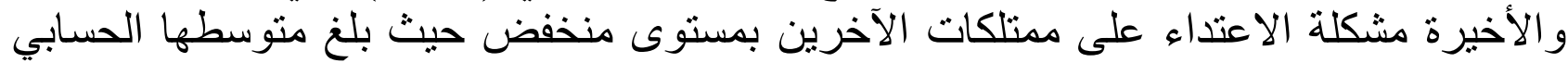
(2.32 ) وبالنسبة للمجموع الكلي للمشكلات السلوكية كان منوسطا حيث بلغ المنغ المتوسط الحسابي

ثانيا: المتوسطات الحسابية و الانحر افات المعيارية ومستوى المشكلات السلوكية بالنسبة لعبارات

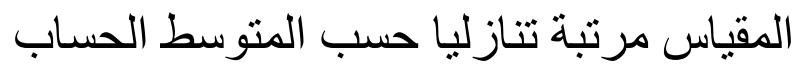

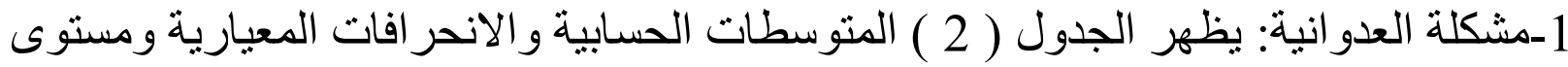
مشكلة العدو انية حسب فقرات هذه المشكلة مرتبة تنازليا حسب المتوسط الحسابية الحسبي.

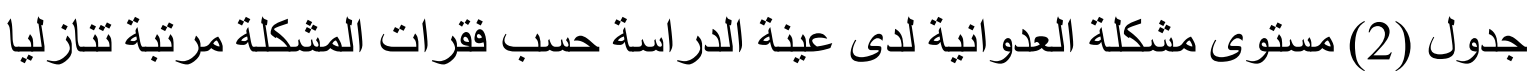

\begin{tabular}{|c|c|c|c|c|}
\hline 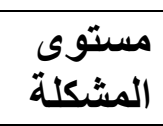 & الالمعراف إن & المتوسط المبي & العبارة & r \\
\hline متوسط & 1.16 & 3.37 & يميل إلى الغضب بسر عة. & 1 \\
\hline متوسط & 1.06 & 3.01 & يتشاجر مع زملائه باستمر ار. & 2 \\
\hline متوسط & 1.06 & 2.75 & يبدو عنيفا عند اللعب مع زملائه. & 3 \\
\hline متوسطة & 1.07 & 2.56 & يبادر بالاعتداء على الآخرين. & 4 \\
\hline متوسط & 1.13 & 2.50 & والثتخدم الإشار ات العدوانية مع زملائه كالضرب و السب & 5 \\
\hline منخفض & 1.12 & 2.18 & يقذف الآخرين بالأشياء التي في يده. & 6 \\
\hline
\end{tabular}




\begin{tabular}{|c|c|c|c|c|}
\hline منخفض & 1.06 & 2.16 & يعتدي على ممتلكات زملائه. & 7 \\
\hline منخفضة & 1.11 & 2.13 & يخرب أثناث الصف المدرسي. & 8 \\
\hline منخفض & 1.08 & 2.00 & يمزق كتبه أو أدواته المدرسية. & 9 \\
\hline متوسط & .88 & 2.52 & المجموع المجوع & \\
\hline
\end{tabular}

يتضح للباحثة من خلال الجدول السابق أن مستوى مشكلة العدوانية للطلبة المعاقين سمعيا من فئن

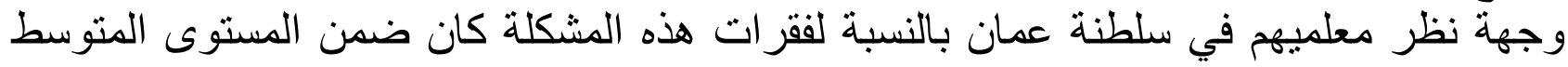
و المنخفض حيث ثر اوح المتوسط الحسابي بين (3.37) و(2.00) و انحر اف معياري بين (1.16) و(1.08) حيث جاء في المرتبة الأولى عبارة" يميل إلى الغضب بسر عة. " بمستوى متوسط وفي المرتبة الثانية عبارة" يتشاجر مع زملائه باستمرار." وبمستوى متوسط أيضا وفي المرة المرتبة

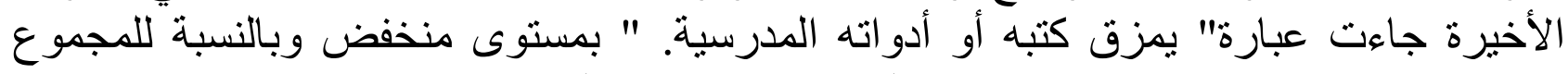
الكلي لمستوى مشكلة العدو انية كان منوسطا حيث بلغ المتوسط الحسابي (2.52).

2-مشكلة النشاط الز ائد

حيث بظهر الجدول (3) المتوسطات الحسابية والانحر افات المعيارية ومستوى مشكلة النشاط الز ائد لدى عينة الدر اسة بالنسبة لفقر ات هذه المشكلة مرتبة تنازليا حسب المتوسط الحسبابي جدول (3) مستوى مشكلة النشاط الز ائد لدى عينة الدر اسة حسب فقر ات المشكلة مرتبة تنازليا

\begin{tabular}{|c|c|c|c|c|}
\hline مستوى & الالنحراف افي المعي & المتوسط المبي & 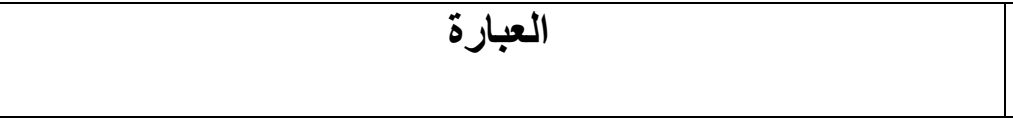 & b \\
\hline متوسط & 1.24 & 3.14 & يتحدث بصوت عال. & 1 \\
\hline 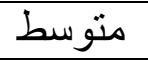 & 1.10 & 3.04 & يتحرك كثير ا أثناء الحصة الدر اسية. & 2 \\
\hline 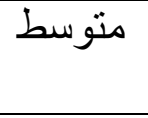 & 1.21 & 2.63 & الإشارة. زماكس زملاءه أثناء الدرس (يقاطعهم، يحادثه، يثير إليهم) بلغة & 3 \\
\hline 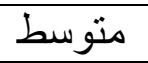 & 1.16 & 2.56 & يحدث الفوضى و الضجيج باستمر ار. & 4 \\
\hline 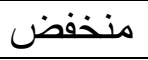 & 1.07 & 2.31 & يخطف الأشياء من أيدي زملائه. & 5 \\
\hline 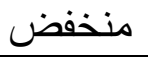 & 1.01 & 2.10 & يكثر من الأسئلة الاستفز ازية للمعلم باستخدام لغة الإشارة. & 6 \\
\hline متوسط & .90 & 2.63 & المجموع الكلي & \\
\hline
\end{tabular}

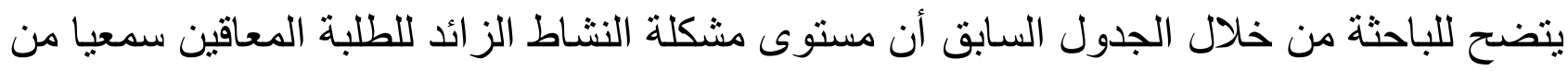
وجهة نظر معلمبهم في سلطنة عمان بالنسبة لفقر ات هذه المشكلة كان ضمن المستوى المتوسط مان و المنخفض حيث تراوح المتوسط الحسابي بين (3.14) و(2.10) وانحر اف معياري بين (1.24) و(1.01) حيث جاء في المرتبة الأولى عبارة" يتحدث بصوت عال. " بمستوى متوسط وفي

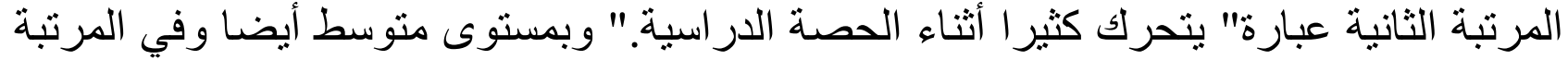
الأخيرة جاءت عبارة" يكثر من الأسئلة الاستفزازية للمعلم باستخدام لغة الإشارة. " بمستوى مئون

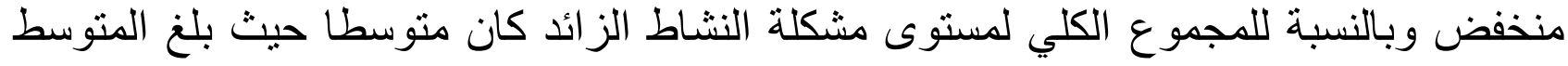

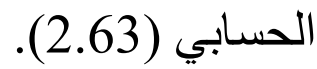
3-مشكلة الاعتداء على ممتلكات الآخرين 
حيث يظهر الجدول (4) المتوسطات الحسايية والانحر افات المعيارية ومستوى مشكلة الاعتداء على ممتلكات الآخرين حسب فقرات هذه المشكلة مرتبة تنازليا حسب المتوسط الحسابي جدول (4) مستوى مشكلة الاعتداء على ممتلكات الآخرين حسب فقرات المشكلة مرتبة تنازليا

\begin{tabular}{|c|c|c|c|c|}
\hline المشكلة & الالتحمياري & المتوسطي المسي & 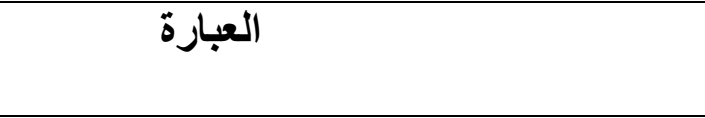 & r \\
\hline متوسط & 1.06 & 3.26 & يكثر الالتفات نحو زملائه و الأشياء التي حوله. & 1 \\
\hline متوسط & 1.04 & 2.56 & يستخدم أدو ات زملائه دون استنذان. & 2 \\
\hline منخفض & 1.05 & 2.25 & يخفي الأشياء التي بعثر عليها & 3 \\
\hline منخفض & 1.12 & 2.15 & يدعي امتلاكه لأشياء ليست لديه في الو اقع. & 4 \\
\hline منخفض & 1.05 & 2.15 & يأخذ أدو ات المدرسة دون إعادتها. & 5 \\
\hline منخفض & 1.04 & 2.06 & يستولي على أدو ات زملائه ويرفض إعادتها. & 6 \\
\hline منخفض & .87 & 1.81 & يفتح حقائب زملائه دون علمهم. & 7 \\
\hline 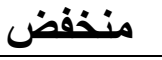 & .84 & 2.32 & المجموع الكلي & \\
\hline
\end{tabular}

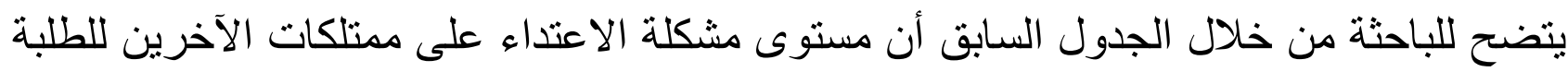

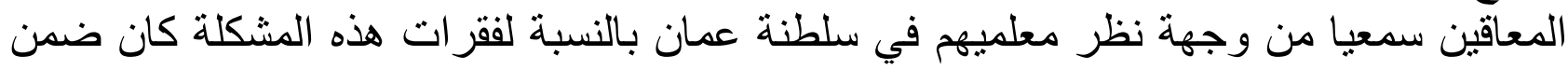

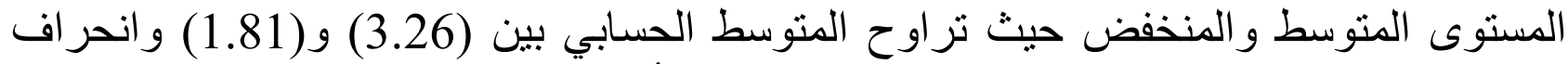

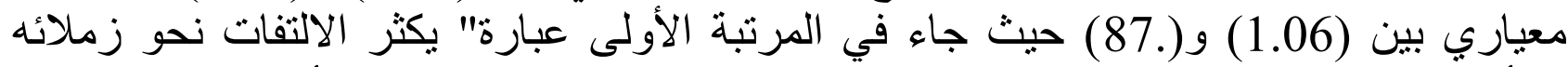

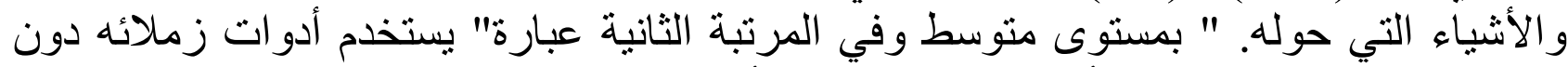

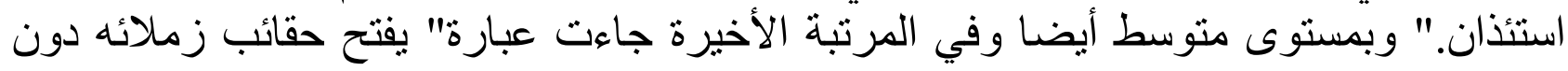

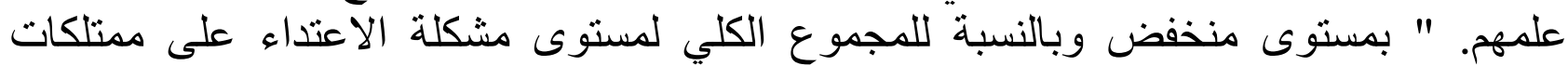
الآخرين كان متوسطا حيث بلغ المتوسط الحسابي (2.32).

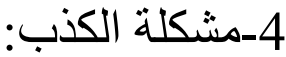

يظهر الجدول (5) المتوسطات الحسابية والانحر افات المعيارية ومستوى مشكلة الكذب حسب

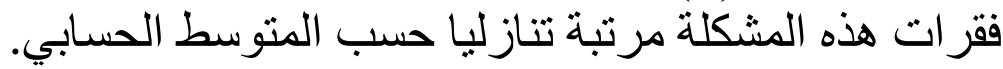
جدول (5) مستوى مشكلة الكذب حسب فقرات هذه المشكلة مرتبة تنازليا حسب المتوسط

\begin{tabular}{|c|c|c|c|c|}
\hline المشتوى & الأنحر افـ & المتوسط المسابي & 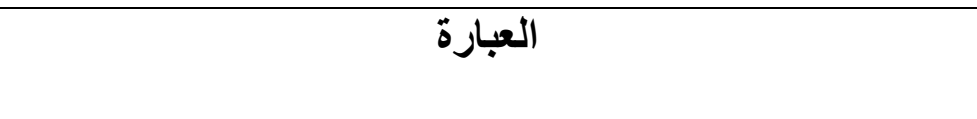 & $\hat{r}$ \\
\hline 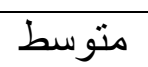 & 1.14 & 2.52 & يزيف الحقائق و لا يعترف بخطئه. & 1 \\
\hline متوسط & 1.23 & 2.46 & يؤلف خيالات ويدعي باستخدام لغة الإشارة أنها حدثت في & 2 \\
\hline متوسط & 1.08 & 2.42 & يكذب كثير ا. & 3 \\
\hline متوسط & 1.19 & 2.37 & يحكي قصصا غير و اقعية عن نفسه باستخدام لغة الإشارة. & 4 \\
\hline منخفض & 1.02 & 2.20 & يتهم المعلم أو زملاءه باتهامات كاذبة. & 5 \\
\hline 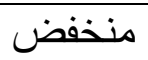 & .99 & 2.12 & ينسب لنفسه أعمالا قام بها غيره. & 6 \\
\hline متوسط & .90 & 2.35 & 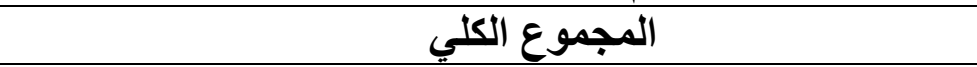 & \\
\hline
\end{tabular}


يتضح للباحثة من خلال الجدول السابق أن مستوى مشكلة الكذب للطلبة المعاقين سمعيا من وجهة نظر معلميهم في سلطنة عمان بالنسبة لفقرات هذه المشكلة كان ضمن المستوى المتوسط فئ و المنخفض حيث ثر اوح المتوسط الحسابي بين (2.52) و(2.12) و انحر اف معياري بين (1.14) و(.99) حيث جاء في المرتبة الأولى عبارة" يزيف الحقائق ولا يعترف بخطئه. " بمستوى متوسط وفي المرتبة الثانية عبارة" يؤلف خيالات وبدعي باستخدام لغة الإشارة أنها حدثت في الو اقع." وبمستوى منوسط أيضا وفي المرتبة الأخيرة جاءت عبارة" ينسب لنفسه أعمالا قام بها غيره. " بمستوى منخفض وبالنسبة للمجموع الكلي لمستوى مشكلة الكذب كان منوسطا حيث بلغ

المتوسط الحسابي (2.35). 5-مشكلة الانسحاب الاجتماعي:

حيث يظهر الجدول (6) المتوسطات الحسابية والانحر افات المعيارية ومستوى مشكلة الانسحاب

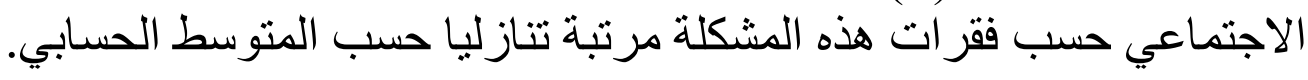

جدول (6) مستوى مشكلة الانسحاب الاجتماعي حسب فقر ات هذه المشكلة مرتبة تنازليا

\begin{tabular}{|c|c|c|c|c|}
\hline المشتوى & الانحرياري & الحستوسطي & 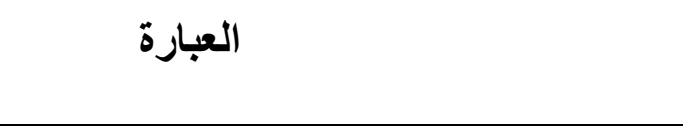 & م \\
\hline 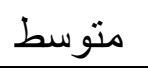 & .97 & 2.71 & يتهرب من مواجهه المو اقف الجديدة. & 1 \\
\hline 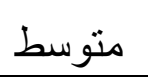 & 1.05 & 2.55 & يرفض الاشتر الك في الأنثطة المدرسية. & 2 \\
\hline 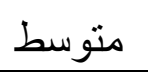 & 1.04 & 2.44 & يشعر بأنه لا أهمية له في المجتمع المدرسي. & 3 \\
\hline منخفض & .88 & 2.19 & يرفض الذهاب إلى المدرسة. & 4 \\
\hline 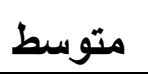 & .69 & 2.47 & 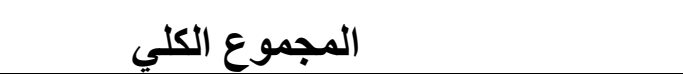 & \\
\hline
\end{tabular}

يتضح من خلال الجدول السابق أن مستوى مشكلة الانسحاب الاجتماعي للطلبة المعاقين سمعبا من هن وجهة نظر معلميهم بالنسبة لفقرات هذه المشكلة كان ضمن المستوى المتوسط و المنخفض حيث الثئ

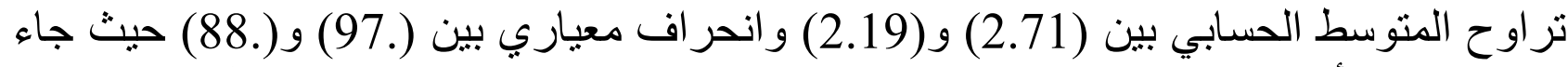
في المرتبة الأولى عبارة" يتهرب من مواجها المواقف الجديدة " بمستوى متوسط وفي المرتبة الثانية عبارة" يرفض الاشترالك في الأنشطة المدرسية." وبمستوى منوسط أيضا وفي المرتبة الأخيرة جاءت عبارة" يرفض الذهاب إلى المدرسة. " بمستوى منخفض وبالنسبة للمجموع الإنية الكئي لمستوى مشكلة الانسحاب الجماعي كان متوسطا حيث بلغ المنوسط الحسابي (2.47). جدول (7) العو امل التي يمكن أن تساهم في الحد من المشكلات السلوكية للمعاقين سمعيا (ن) (199

\begin{tabular}{|c|c|c|c|}
\hline المئوية النسبة & 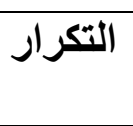 & الإجابة & r \\
\hline 18,1 & 36 & معاملة هذه الفئة من الطلاب بكل احتر ام ولطف ومحبه & 1 \\
\hline 13,56 & 27 & التو اصل المستمر بين المدرسة والأسرة & 2 \\
\hline 12,56 & 25 & مشاركة الطلاب المعاقين سمعيا في الأنشطة التي تقيمها المدرسة مع & 3 \\
\hline
\end{tabular}




\begin{tabular}{|c|c|c|c|}
\hline & & الطلاب العاديين & \\
\hline 12,06 & 24 & داخل وخار الطلاب الصدر مع الطلاب العاديين في جميع الفعاليات و المناسبات & 4 \\
\hline 11,05 & 22 & هذه الفئة من في طر الئق التدريس داخل الغرفة الصفية للتناسب حاجات وميول & 5 \\
\hline 9,54 & 19 & تفعيل لغة الإشارة عن التعامل مع هذه الفئة سواء داخل أو خارج & 6 \\
\hline 8,04 & 16 & تطوير المناهج الدر اسية بما يتناسب مع خصائص هؤلاء الطلاب & 7 \\
\hline 6,53 & 13 & تعنيين أخصابئيين اجتماعبين ونفية التعامل معهين من اجل معرفة حاجات هذه الفئة & 8 \\
\hline 4,52 & 9 & ضرورة تعيين معلم نطق في كل مدرسة & 9 \\
\hline 4,02 & 8 & الكعامل مع هذه الفئة في الطعلاب المدارس بعض المهارات الضرورية في كيفية & 10 \\
\hline
\end{tabular}

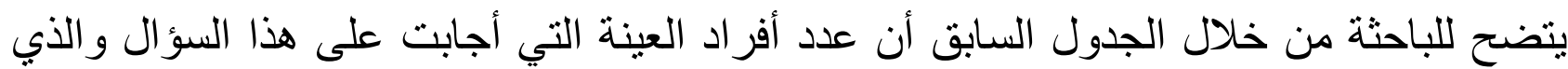

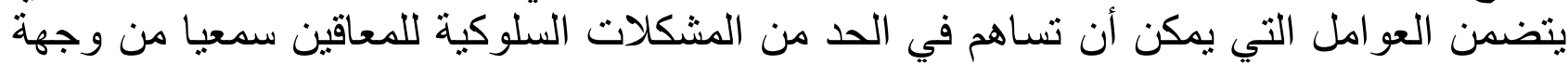

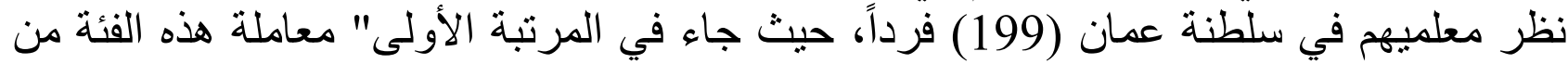

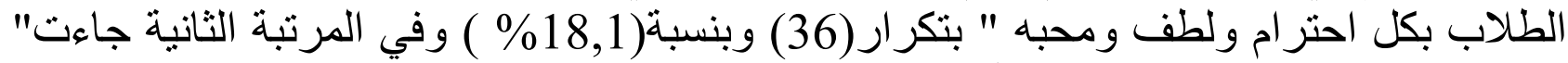

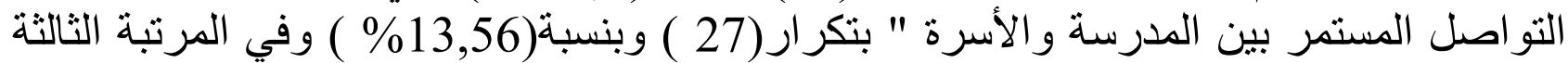

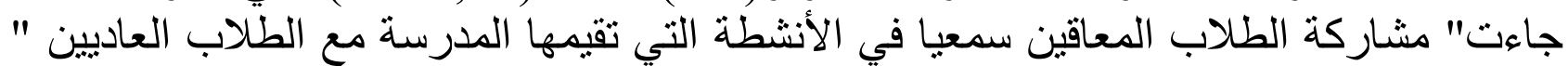

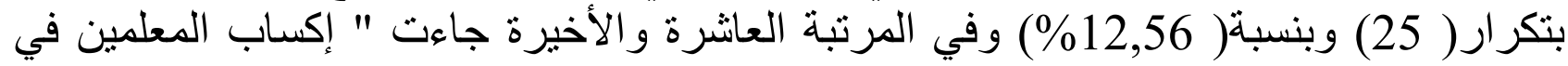

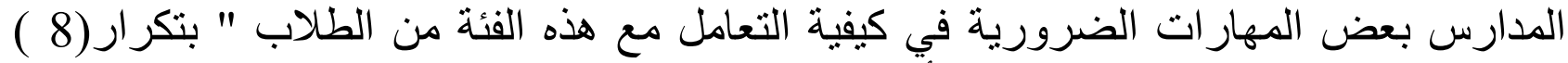

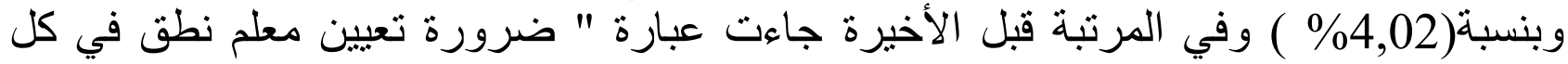

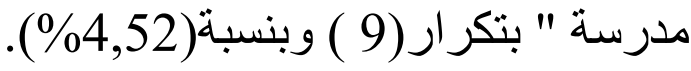

التوصيات: أ. تفعيل لغة الإشارة في المجتمع المدرسي. ب. دمج المعاقين سمعيا دمجا كليا في المجتمع المدرسي من حيث (طابور الصني الصباح، و المشاركة في الأنشطة المدرسية).

قائمة المر اجع:

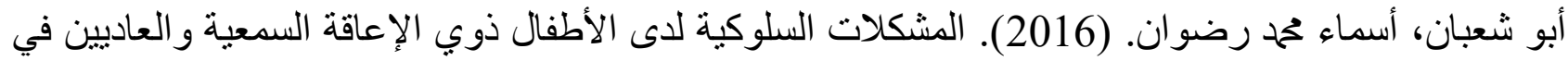
قطاع غزة (رسالة ماجستير في الصحة النفسية والمجتمعية غير منشورة). غزة: كلية التربية. الجامعة الإنة الإسلامية.

الخطيب، جمال محح؛ و الحديدي، منى صبحي. (2009). المدخل إلى التربية الخاصة. عمَان: دار الفكر.

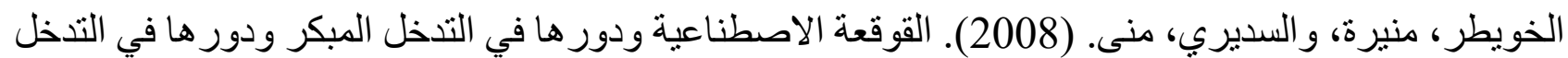

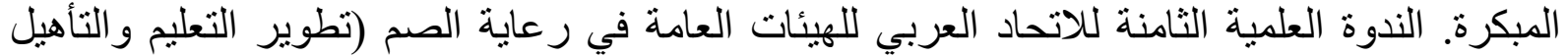

للأشخاص الصم وضعاف الندوة السمع). السواح، صالح عبد المقصود. (2009). تعديل سلوك الأطفال المعاقين سمعيا. ط1. الإسكندرية: دار الوفاء 
الصفدي، عصام حمدي. (2003). الإعاقة السمعية. الأردن: در البازوري العلمية للنشر والتوزيع. الظاهر، قحطان أحمد. (2008). مدخل إلى التربية الخاصة. ط2. الأردن: دار و ائل للنشر. العساف، صالح حمد. (2006). دليل الباحث في العلوم السلوكية. الرياض: مكتبة العبيكان. العقباوي، أحلام. (2010). سيكولوجية الطفل الأصم. القاهرة: مكتبة الأنجلو المصرية. القمش، مصطفى نوري؛ و المعايطة، خليل عبد الرحمن. (2009). الاضطر ابات السلوكية والانفعالية. عمَان: دار المسيرة للنشر.

رسلان، شاهين. (2009). سيكولوجية الإعاقات العقلية والحسية (التشخيص و العلاج). القاهرة: مكتبة الأنجلو المصرية. زهر ان، حامد. (2005). الصحة النفسية والعلاج النفسي. ط4. القاهرة: عالم الكتب للنشر. سليمان، عبد الرحمن سيد. (1999). سيكولوجية ذوي الحاجات الخاصة (المفهوم و الفئات). القاهرة: مكتبة ز زهر اء الثرق.

طه، نجاة فتحي سعيد. (2017). الإعاقة السمعية و عادات العقل. القاهرة: مكتبة الأنجلو المصرية للنشر.

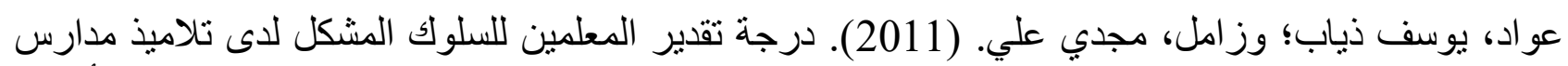
وكالة الغوث الدولية في محافظة نابلس وسبل علئ علاجها (رسالة ماجستير). فلسطين: مجلة جامعة الأزهر.

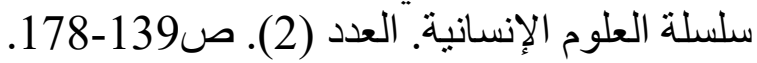

كو افحة، تيسير مفلح، و عبد العزيز، عمر فؤاد. (2010). مقدمة في التربية الخاصة. ط4. الأردن: دار المسيرة

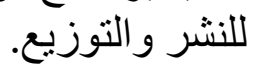
مختار، و فيق صفوت. (1999). مشكلات الأطفال السلوكية. القاهرة: دار العلم و الثقافة للنشر. فهمي، مصطفى. (1985). سيكولوجية الأطفال غير العاديين. القاهرة: مكتبة مصر للنشر و التوزيع. موسى، رشاد علي عبد العزيز. (2009). سيكولوجية المعاق سمعيا. ط1. القاهرة: عالم الكتب للنشر و التوزيع. نيسان، خالدة. (2017). الإعاقة السمعية دن مفهوم تأهيلي. ط1. الأردن: دار أسامة للنشر و التوزيع.

\section{ARABIC REFERENCES IN ROMAN ALPHABET}

'Abu Shaeiban, 'Asma' Muhamad Ridwan. (2016). Almushkilat Alsilukiat Ladaa Al'atfal Dhwya Al'iieaqat Alsameiat Waleadiiyn fi Qitae Ghaza (Rsalat Majstir fi Alsihat Alnafsiat Walmujtameiat Ghyr Munshurata). Ghazata: Kuliyat Altarbiati. Aljamieat Al'iislamiat.

Alkhatib, Jamal Muhmada; Walhadidi, Munaa Subhi. (2009). Almudkhal 'lilaa Altarbiat Alkhasati. Eman: Dar Alfikr.

Alkhawaytr, Munirat, Walsadiri, Manaa. (2008). Alqawqieat Alaistinaeiat Wadawruha Fi Altadakhul Almubakir Wadawriha fi Altadakhul Almubkirati. Alnadwat Aleilmiat Alththaminat Lilaitihad Alearabii Lilhayyaat Aleamat fi Rieayat Alsumi (Ttawir Altaelim Waltaahil Lil'ashkhas Alsumi Wadaeaf Alsame).

Alsawah, Salih Eabd Almuqsawud. (2009). Taedil Suluk Al'atfal Almueaqin Samieya. T1. Al'iiskandariat: Dar Alwafa' Lilnashrr.

Alsafdi, Eisam Humdy. (2003). Al'iieaqat Alsameiatu. Al'urduna: Dur Albazury Aleilmiat Lilnashr Waltawzie.

Alzaahir, Qahtan 'Ahmud. (2008). Madkhal 'lilaa Altarbiat Alkhasat. Ta2. Al'urduna: Dar Wayil Lilnashrr.

Aleasaf, Salih Hamd. (2006). Dalil Albahith fi Aleulum Alsilukiati. Alriyad: Maktabat Aleubykan.

Aleaqbawi, 'Ahlam. (2010). Saykulujiat Altifl Al'asmu. Alqahirt: Maktabat Al'anjilu Almisriat. Alqumsh, 
Mustafaa Nuri; Walmueayitat,

Khalil Eabd Alrahmun. (2009). Alaidtirabat Alsilukiat Walainfiealiatu. Eman: Dar Almasirat Lilnashr.

Rusalan, Shahin. (2009). Sayakulujiat Al'iieaqat Aleaqliat Walhasia (Altashkhis Walealaja). Alqahirat: Maktabat Al'anjilu Almisriat.

Zihran, Hamid. (2005). Alsihat Alnafsiat Waleilaj Alnafsi. Ta4. Alqahirat: Ealam Alkutub Lilnashrr.

Sulayman, Eabd Alruhmin Sayid. (1999). Saykulawjiat Dhwyu Alhajat Alkhasa (Almafhum Walfiaata). Alqahirat: Maktabat Zuhra' Alsharq.

Tah, Najat Fathi Sueyd. (2017). Al'iieaqat Alsameiat Waeadat Aleaql. Alqahrt: Maktabat Al'anjilu Almisriat Lilnashr.

Eawad, Yusif Dhiab; Wazamil, Majdi Eali. (2011). Darajat Taqdir Almuealimin Lilsuluk Almushakil Ladaa Talamidh Madaris Wikalat Alghawth Alduwaliat fi Muhafazat Nabulus Wasubul Eilajiha (Rsaalat Majstayra). Filastina: Majalat Jamieat Al'azahir. Silsilat Aleulum Al'iinsaniat. Aleadad (2). Sa139-178.

Kawafihat, Taysir Muflih, Waeabd Aleaziz, Eumar Fawaada. (2010). Muqadimat fi Altarbiat Alkhasat. T4. Al'urduna: Dar Almasirat Lilnashr Waltawzie.

Mikhtar, Wafiq Safut. (1999). Mushkilat Al'atfal Alsilukiatu. Alqahirat: Dar Aleilm Walthaqafat Lilnashr.

Fahami, Mustafaa. (1985). Saykulujiat Al'atfal Ghyr Aleadiayina. Alqahrt: Maktabat Misr Lilnashr Waltawzie.

Musaa, Rashad Ealia Eabd Aleaziz. (2009). Saykulujiat Almaeaq Samieya. Ta1. Alqahirat: Ealam Alkutub Lilnashr Waltawzie.

Nayasan, Khalidut. (2017). Al'iieaqat Alsameiat Min Mafhum Tahili. T1. Al'urduna: Dar 'Usamat Lilnashr Waltawzie.

\section{REFERENCE LIST}

Chin-Chih, Chen. (2008). Predictors of behavioral problems for Students With high -incidence disabilities. United States: Ann Arbor.

Vostanis, Panos, Du Feu, Margaret. (2006). Behavioral and emotional problems in hearing impaired children: a preliminary study of teacher and parent ratings. Published online. Dutch Foundation for Deaf and Hearing-Impaired Children, Amsterdam, Netherlands. 